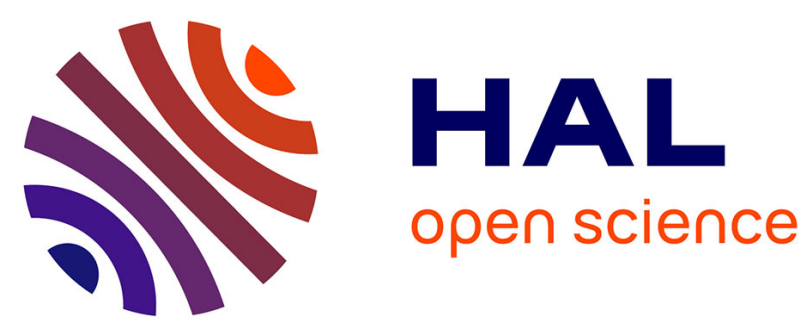

\title{
Lewis acid catalysis and Green oxidations: sequential tandem oxidation processes induced by Mn-hyperaccumulating plants
}

\author{
Vincent Escande, Brice-Loïc Renard, Claude Grison
}

\section{- To cite this version:}

Vincent Escande, Brice-Loïc Renard, Claude Grison. Lewis acid catalysis and Green oxidations: sequential tandem oxidation processes induced by Mn-hyperaccumulating plants. Environmental Science and Pollution Research, 2015, Combining Phytoextraction and Ecological Catalysis: an Environmental, Ecological, Ethic and Economic Opportunity, 22 (8), pp.5633 - 5652. 10.1007/s11356-014-3631-z . hal-01937632

\section{HAL Id: hal-01937632 \\ https://hal.umontpellier.fr/hal-01937632}

Submitted on 23 Feb 2021

HAL is a multi-disciplinary open access archive for the deposit and dissemination of scientific research documents, whether they are published or not. The documents may come from teaching and research institutions in France or abroad, or from public or private research centers.
L'archive ouverte pluridisciplinaire HAL, est destinée au dépôt et à la diffusion de documents scientifiques de niveau recherche, publiés ou non, émanant des établissements d'enseignement et de recherche français ou étrangers, des laboratoires publics ou privés. 


\title{
Lewis acid catalysis and Green oxidations: sequential tandem oxidation processes induced by Mn-hyperaccumulating plants
}

\author{
Vincent Escande • Brice-Loïc Renard • Claude Grison
}

\begin{abstract}
Among the phytotechnologies used for the reclamation of degraded mining sites, phytoextraction aims to diminish the concentration of polluting elements in contaminated soils. However, the biomass resulting from the phytoextraction processes (highly enriched in polluting elements) is too often considered as a problematic waste. The manganese-enriched biomass derived from native $\mathrm{Mn}$ hyperaccumulating plants of New Caledonia was presented here as a valuable source of metallic elements of high interest in chemical catalysis. The preparation of the catalyst Eco- $\mathrm{Mn}_{1}$ and reagent Eco- $\mathrm{Mn}_{2}$ derived from Grevillea exul exul and Grevillea exul rubiginosa was investigated. Their unusual polymetallic compositions allowed to explore new reactivity of low oxidative state of manganese- $\mathrm{Mn}$ (II) for Eco- $\mathrm{Mn}_{1}$ and $\mathrm{Mn}(\mathrm{IV})$ for Eco-Mn $\mathrm{Mn}_{2}$ Eco-Mn $\mathrm{Mn}_{1}$ was used as a Lewis acid to catalyze the acetalization/elimination of aldehydes into enol ethers with high yields; a new green and stereoselective synthesis of (-)-isopulegol via the carbonyl-ene cyclization of (+ )-citronellal was also performed with Eco- $\mathrm{Mn}_{1}$. Eco- $\mathrm{Mn}_{2}$ was used as a mild oxidative reagent and controlled the oxidation of aliphatic alcohols into aldehydes with quantitative yields. Oxidative cleavage was interestingly noticed when Eco- $\mathrm{Mn}_{2}$ was used in the presence of a polyol. Eco- $\mathrm{Mn}_{2}$ allowed direct oxidative iodination of ketones without using iodine, which is strongly discouraged by new environmental legislations. Finally, the combination of the properties in the Eco-Mn catalysts and reagents gave them an unprecedented potential to perform sequential tandem oxidation processes through new green syntheses of $p$-cymene from (-)-isopulegol and (+)-
\end{abstract}

V. Escande $\cdot$ B.-L. Renard · C. Grison $(\bowtie)$

Laboratoire de Chimie bio inspirée et Innovations écologiques, FRE 3673 ChimEco CNRS-UM2, Stratoz, Cap Alpha-Avenue de l'Europe, Clapiers, 34830 Montpellier, France

e-mail: claude.grison@cnrs.fr citronellal; and a new green synthesis of functionalized pyridines by in situ oxidation of 1,4-dihydropyridines.

Keywords Phytoextraction · Green chemistry · Tandem oxidation · Lewis acid catalysis · Manganese - Ecocatalysis · Metal-hyperaccumulating plants

\section{Introduction}

The chemistry of manganese is largely known for the high oxidation state of $\mathrm{Mn}$ that is $\mathrm{Mn}(\mathrm{VII})$, and thus for the oxidative abilities of $\mathrm{KMnO}_{4}$ (Lee et al. 2001). Until recently, the lower oxidation states, $\mathrm{Mn}(\mathrm{IV}), \mathrm{Mn}(\mathrm{III})$, and $\mathrm{Mn}(\mathrm{II})$ were less used in organic synthesis. $\mathrm{MnO}_{2}$ has led to more restricted outlet in synthesis than $\mathrm{KMnO}_{4}$, because it needs to be prepared under active form for displaying its oxidizing properties. It has been found to be a mild oxidizing agent with a low reactivity (Cahiez et al. 2001a). Application of Mn(III) in organic chemistry has recently emerged, especially in radical reactions (Snider et al. 2001). As $\mathrm{Mn}$ (II) is considered as a weak Lewis acid (Cahiez et al. 2001b), its use in catalysis remains limited.

Besides, the development of "Ecocatalysis", which has been initiated by our group (Escande et al. 2014a; Grison and Escande 2013a, b; Grison et al. 2013; Grison and Escarré 2011; Losfeld et al. 2012), has already shown unexpected outstanding reactivity of Lewis acids in ecocatalysts derived from hyperaccumulating plants. For instance, commercial $\mathrm{NiCl}_{2}$ is considered as a weak Lewis acid, but Eco-Ni has shown very strong Lewis acid properties and has allowed the catalysis of unprecedented green reductions. The new reactivity of ecocatalysts has been explained by the synergic effect of other cationic metals, hyperaccumulated by the plants. Therefore, new applications of low oxidation states of $\mathrm{Mn}$ in organic 
chemistry were explored here through an alternative resource of Mn derived from Mn-hyperaccumulating plants.

In the present work, Mn-hyperaccumulating plants $(>1 \%$ of $\mathrm{Mn}(w / w)$ in dry leaf tissue (Baker and Brooks 1989; van der Ent et al. 2013)) were cultivated on New Caledonian sites, which had been degraded by the mining industry. Among the Mn-hyperaccumulating species present in New Caledonia (Brooks et al. 1981; Fernando et al. 2008; Jaffre 1977, 1979), Grevillea exul (Proteaceae) was a pioneering plant in revegetation trials, capable of growing rapidly and able to hyperaccumulate the highest concentration of $\mathrm{Mn}$ in shoots. $G$. exul were thus cultivated on such polluted sites in a phytoextraction process to provide a rich source of manganese and others transition metals. The conversion of $G$. exul shoots into ecocatalysts produced Eco- $\mathrm{Mn}_{1}$ and Eco-Mn $\mathrm{Mn}_{2}$, composed of Mn(II) and Mn(IV), respectively. Their detailed compositions were investigated by inductively coupled plasma mass spectrometry (ICP-MS) and X-ray diffraction (XRD) analyses before use in organic synthesis. The unusual polymetallic species present in Eco- $\mathrm{Mn}_{1}$ and in Eco- $\mathrm{Mn}_{2}$, showed respectively unprecedented strong Lewis acid properties of $\mathrm{Mn}$ (II) and a controlled oxidative reactivity of Mn(IV) strengthened by the presence of Lewis acids in the plant-based extract. The combination of the two factors allowed the Eco-Mn to promote sequential tandem reactions of acid catalysis/oxidation.

\section{Materials and methods}

Chemicals

Reagents and solvents were purchased from Sigma-Aldrich and were used without further purification.

Preparation of Eco-Mn

Preparation of Eco- $M n_{1}$

Two subspecies of $G$. exul are present in New Caledonia: G. exul exul and G. exul rubiginosa (Jaffre 1979), being both capable of hyperaccumulating manganese. In order to compare the possible differences in manganese accumulation, two Eco$\mathrm{Mn}_{1}$ have been prepared, derived from the two subspecies.

Leaves of $G$. exul (same treatment for ssp. exul and rubiginosa) were harvested before flowering in the Southern Province of the subtropical Pacific island of New Caledonia, in homogeneous vegetal populations. $G$. exul exul was collected in Camp des sapins mining site, near Thio; G. exul rubiginosa was collected at Col de Mouriange, near Le Mont-Dore. The leaves were air-dried and grounded. The obtained solid (50 g) was calcined to $400{ }^{\circ} \mathrm{C}$ for $5 \mathrm{~h}$ and the resulting powder $(1.5 \mathrm{~g})$ was added to $20 \mathrm{~mL}$ of a diluted solution of $\mathrm{HCl}(1 \mathrm{M})$. The solution was stirred for $2 \mathrm{~h}$ at $60{ }^{\circ} \mathrm{C}$. During heating, the color of the mixture evolved from black to dark green. The reaction mixture was then filtered on a pad of celite. The resulting dark-green solution, composed of different metal chlorides, was concentrated under vacuum, yielding Eco- $\mathrm{Mn}_{1}$ as a pale yellow powder ( $2.09 \mathrm{~g}$ from $G$. exul exul, $2.25 \mathrm{~g}$ from G. exul rubiginosa). The resulting Eco- $\mathrm{Mn}_{1}$ catalyst was stored in a desiccator under vacuum. Purification steps are not mandatory in our process.

\section{Preparation of Eco- $\mathrm{Mn}_{2}$}

The preparation of Eco- $\mathrm{Mn}_{2}$ relied on the oxidation of $\mathrm{Mn}$ (II) from Eco- $\mathrm{Mn}_{1}$ into $\mathrm{Mn}(\mathrm{IV})$, by dioxygen from air at atmospheric pressure, in slightly alkaline medium. Following the Pourbaix diagram of manganese (Fig. 1), the standard potential of $\mathrm{Mn}(\mathrm{IV}) / \mathrm{Mn}(\mathrm{II})$ decreases when $\mathrm{pH}$ increases. At $\mathrm{pH} 8$, $\mathrm{Mn}$ (II) formed a precipitate under the form of $\mathrm{Mn}$ (II) hydroxide $\left(\mathrm{Mn}(\mathrm{OH})_{2}\right)$. The standard potential of $\mathrm{O}_{2} / \mathrm{H}_{2} \mathrm{O}$ was higher than the standard potential of $\left(\mathrm{Mn}(\mathrm{OH})_{2}\right)$ at $\mathrm{pH}$ 8. The oxidation of $\mathrm{Mn}(\mathrm{II})$ by dioxygen was then possible and led to $\mathrm{Mn}_{3} \mathrm{O}_{4}$ and $\mathrm{Mn}_{2} \mathrm{O}_{3}$. The oxidation of $\mathrm{Mn}$ (II) into $\mathrm{Mn}_{2} \mathrm{O}_{3}$ ( $\mathrm{Mn}(\mathrm{III}))$ and $\mathrm{Mn}_{3} \mathrm{O}_{4}(\mathrm{Mn}(\mathrm{II}, \mathrm{III})$ ) was rapidly visible, as the solution turns from light yellow to black in a few hours (Fig. 2). As Fe(III) was also present in the starting Eco- $\mathrm{Mn}_{1}$ catalyst, it was equally precipitated into $\mathrm{Fe}_{2} \mathrm{O}_{3}$, following its Pourbaix diagram (Fig. 3).

$\mathrm{Mn}_{2} \mathrm{O}_{3}(\mathrm{Mn}(\mathrm{III}))$ and $\mathrm{Mn}_{3} \mathrm{O}_{4}(\mathrm{Mn}(\mathrm{II}, \mathrm{III}))$ were eliminated by disproportionation into $\mathrm{Mn}^{2+}(\mathrm{Mn}(\mathrm{II}))$ and $\mathrm{MnO}_{2}(\mathrm{Mn}(\mathrm{IV}))$ by acidification at $\mathrm{pH} 3$, according to the following equations (Artamonova et al. 2013):

$\mathrm{Mn}_{3} \mathrm{O}_{4}+2 \mathrm{H}^{+} \rightarrow \mathrm{Mn}^{2+}+\mathrm{Mn}_{2} \mathrm{O}_{3}+\mathrm{H}_{2} \mathrm{O}$

$\mathrm{Mn}_{2} \mathrm{O}_{3}+2 \mathrm{H}^{+} \rightarrow \mathrm{Mn}^{2+}+\mathrm{MnO}_{2}+\mathrm{H}_{2} \mathrm{O}$

After acidification at $\mathrm{pH} 3, \mathrm{Fe}_{2} \mathrm{O}_{3}$ was equally transformed into soluble $\mathrm{Fe}^{3+}$ ions. Acidification was performed with diluted hydrochloric acid, Mn(II) and Fe(III) were therefore present as hydrated chlorides in the solution. The final mixture was composed of $\mathrm{MnO}_{2}$ in combination with $\mathrm{Mn}$ (II) and $\mathrm{Fe}$ (III) chlorides, which can act as Lewis acids as observed in Eco- $\mathrm{Mn}_{1}$.

In a typical procedure, $50 \mathrm{mg}$ of Eco- $\mathrm{Mn}_{1}(0.061 \mathrm{mmol}$ of $\mathrm{Mn})$ were introduced in a $25-\mathrm{mL}$ flask. After addition of water $(10 \mathrm{~mL})$, a light yellow solution was obtained. The $\mathrm{pH}$ of the solution was adjusted to 8 by addition of a few drops of aqueous solution of sodium hydroxide $(0.01 \mathrm{M})$. A brownishorange precipitate was immediately formed. The flask was open to air and the solution was stirred at room temperature. After $2 \mathrm{~h}$, the color of the solution became dark brown, then black. No evolution of color was observed after 5 h. After 7 h, 


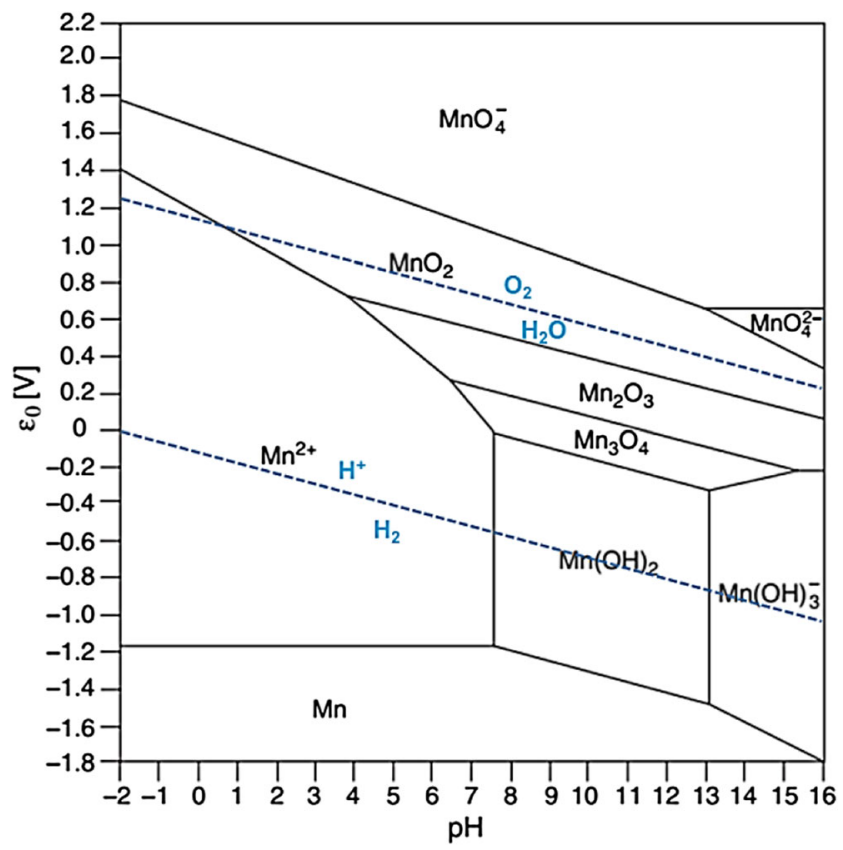

Fig. 1 Pourbaix diagram of manganese. Adapted from Fränzle (2010)

the black solid was collected by centrifugation then washed with water $(3 \times 15 \mathrm{~mL})$ in order to eliminate the excess of sodium hydroxide. After addition of water $(10 \mathrm{~mL})$, the $\mathrm{pH}$ of the solution was then adjusted to $\mathrm{pH} 3$ by addition of a few drops of diluted hydrochloric acid $(0.1 \mathrm{M})$. After evaporation of the liquid phase under reduced pressure, a brilliant black powder was collected, dried, and stored in a vacuum desiccator over $\mathrm{P}_{2} \mathrm{O}_{5}$, yielding $5.5 \mathrm{mg}$ of Eco- $\mathrm{Mn}_{2}$.

\section{Characterization of Eco- $\mathrm{Mn}_{1}$}

ICP-MS was used to determine the composition of Eco- $\mathrm{Mn}_{1}$ and $\mathrm{Eco}-\mathrm{Mn}_{2}$.

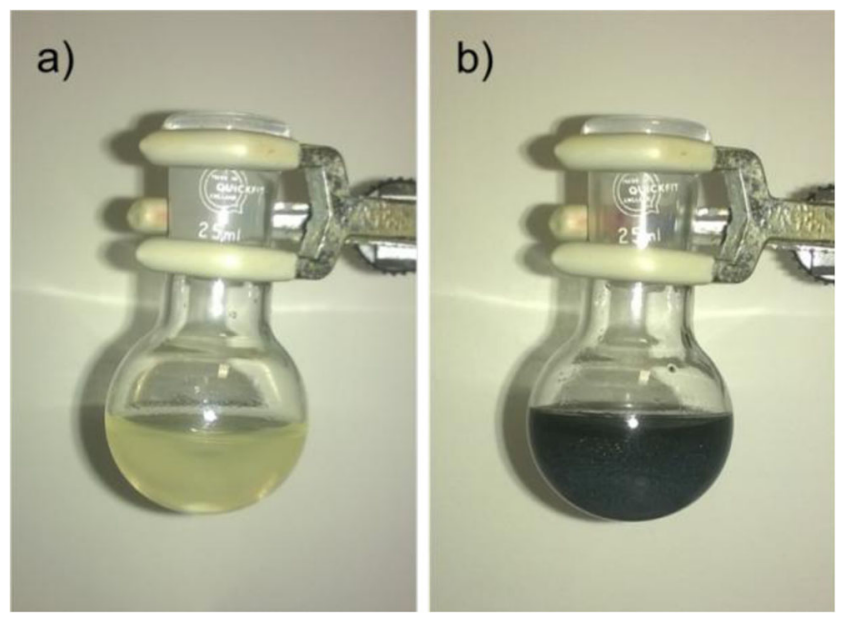

Fig. 2 Oxidation of $\mathrm{Mn}(\mathrm{II})$ from Eco- $\mathrm{Mn}_{1}$ into $\mathrm{Mn}_{2} \mathrm{O}_{3}(\mathrm{Mn}(\mathrm{III}))$ and $\mathrm{Mn}_{3} \mathrm{O}_{4}(\mathrm{Mn}(\mathrm{II}, \mathrm{III}))$ by air: a before basification, b $7 \mathrm{~h}$ of agitation in contact with air at $\mathrm{pH} 8$

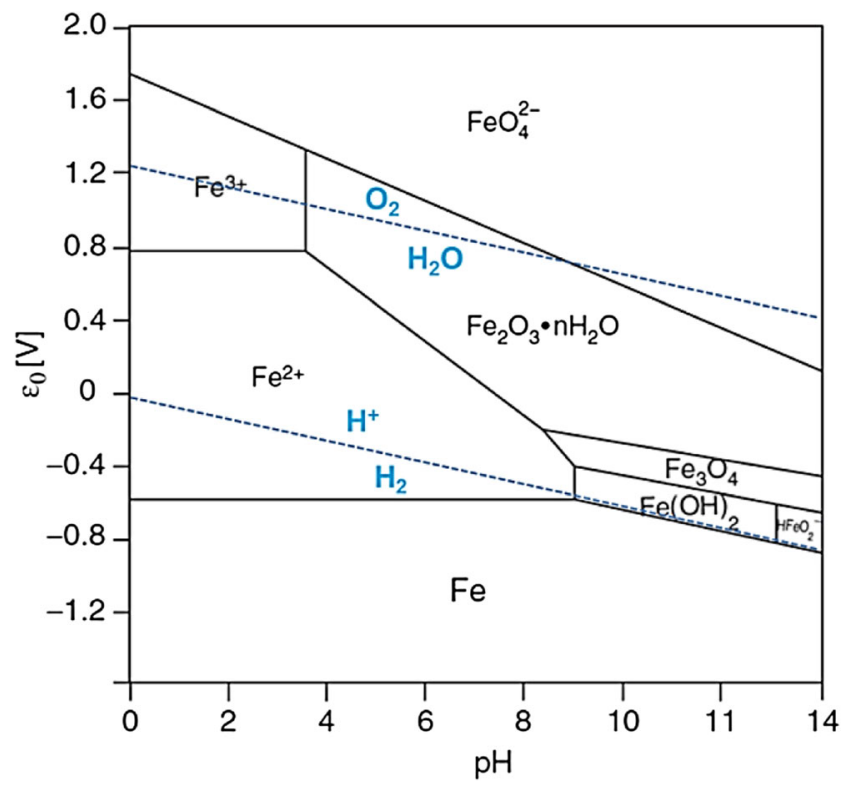

Fig. 3 Pourbaix diagram of iron. Adapted from Fränzle (2010)

ICP-MS analyses were performed using the metal analysis of total dissolved solutes in water. The samples were acidified with nitric acid $2.5 \%$ and stirred for $30 \mathrm{~min}$. The digestates were diluted to $0.005 \mathrm{~g} . \mathrm{L}^{-1}$. Three blanks were recorded for each step of the digestion and dilution procedure on a HRICP-MS Thermo Scientific Element XR. Three analyses were performed for each sample in order to determine the standard deviation of the measurement.

XRD data measurements on the samples dried at $110^{\circ} \mathrm{C}$ for $2 \mathrm{~h}$ were performed by using a BRUKER diffractometer (D8 advance, with a $\mathrm{Cu} \mathrm{K} \alpha$ radiation $\lambda=1.54086^{\circ} \mathrm{A}$ ) equipped with a Lynxeyes detector.

FT-IR measurements were carried out using pyridine as probe molecule. A PerkinElmer Spectrum 100 FT-IR spectrometer was used for recording spectra. Excess gaseous pyridine was adsorbed on the samples, then the samples were degassed for $15 \mathrm{~min}$ at $25^{\circ} \mathrm{C}\left(10^{-3} \mathrm{~Pa}\right)$ and a first spectrum was recorded. The samples were then degassed for $15 \mathrm{~min}$ at $150{ }^{\circ} \mathrm{C}\left(10^{-3} \mathrm{~Pa}\right)$ to eliminate the physisorbed pyridine and a second spectrum was recorded.

\section{Syntheses catalyzed by Eco- $\mathrm{Mn}_{1}$}

\section{Synthesis of alkyl enol ethers from aldehydes}

In a typical procedure, to a solution of aldehyde $(1.0 \mathrm{mmol})$ in anhydrous ethanol $(3.0 \mathrm{~mL})$ was added Eco- $\mathrm{Mn}_{1}(82 \mathrm{mg}$, amount corresponding to $0.10 \mathrm{mmol}$ of $\mathrm{Mn}$ ). The suspension was refluxed for $5 \mathrm{~h}$ (reaction monitored by GC-MS analysis), then without elimination of the catalyst, the mixture was slowly distilled under reduced pressure $(40 \mathrm{mmHg})$ affording the corresponding ethyl enol ether. Spectroscopic data $\left({ }^{1} \mathrm{H}\right.$ 
NMR, IR) were in accordance with the data previously published (Barbot and Miginiac 1979).

\section{Synthesis of isopulegol via the carbonyl-ene cyclization of (+) -citronellal}

To a suspension of Eco-Mn $\mathrm{Mn}_{1}(16.4 \mathrm{mg}$, amount corresponding to $0.020 \mathrm{mmol}$ of $\mathrm{Mn}$ ) in $10 \mathrm{~mL}$ of dichloromethane was added $180.4 \mu \mathrm{L}$ of $(+)$-citronellal $(1.0 \mathrm{mmol})$. After stirring for $0.5 \mathrm{~h}$ under reflux, the reaction mixture was filtered and washed with a saturated aqueous solution of $\mathrm{NaHCO}_{3}$. The organic layer was dried over $\mathrm{Na}_{2} \mathrm{SO}_{4}$, filtered, and concentrated under reduced pressure. A yield of $95 \%$ and $90 \%$ of (-)-isopulegol stereoselectivity were estimated by GC-MS analysis. ${ }^{1} \mathrm{H}$ NMR and IR data were in accordance with those previously reported (Imachi et al. 2007).

\section{Synthesis of p-cymene from (+)-citronellal}

To $5 \mathrm{mg}$ of Eco- $\mathrm{Mn}_{1}$ (amount corresponding to $0.006 \mathrm{mmol}$ of $\mathrm{Mn})$ co-ground with $100 \mathrm{mg}$ of silica gel, was added (+)citronellal $(21.8 \mu \mathrm{L}, 0.12 \mathrm{mmol})$. After stirring for $1 \mathrm{~h}$ at $90^{\circ} \mathrm{C}$, the reaction mixture was washed with dichloromethane and filtered through celite. The solution was concentrated under reduced pressure. A yield of $80 \%$ of $p$-cymene with $5 \%$ of (-)-isopulegol were estimated by GC-MS. $p$-Cymene identification was performed by comparing retention times and MS spectra with a commercial sample.

\section{Synthesis of p-cymene from (-)-isopulegol}

To $15 \mathrm{mg}$ of Eco- $\mathrm{Mn}_{1}$ (amount corresponding to $0.018 \mathrm{mmol}$ of $\mathrm{Mn}$ ) co-ground with $100 \mathrm{mg}$ of silica gel, was added (-)isopulegol $(20 \mu \mathrm{L}, 0.12 \mathrm{mmol})$. After stirring for $1 \mathrm{~h}$ at $90^{\circ} \mathrm{C}$, the reaction mixture was washed with dichloromethane and filtered through celite. The solution was concentrated under reduced pressure. A yield of $91 \%$ of $p$-cymene was estimated by GC-MS. $p$-Cymene identification was performed by comparing retention times and MS spectra with a commercial sample.

\section{Synthesis of diethyl \\ 2,6-dimethyl-4-phenyl-3,5-pyridinedicarboxylate}

In a typical procedure, to a co-ground mixture of silica gel $(1 \mathrm{~g})$ and Eco-Mn $\mathrm{Mn}_{1}(42 \mathrm{mg}$, amount corresponding to $0.05 \mathrm{mmol}$ of $\mathrm{Mn})$ were added benzaldehyde $(51 \mu \mathrm{L}, 0.5 \mathrm{mmol})$, ethyl acetoacetate $(126 \mu \mathrm{L}, 1.0 \mathrm{mmol})$, and ammonium acetate (58 mg, $0.75 \mathrm{mmol}$ ). After homogenization of the mixture with spatula, the resulting white powder was poured into a glass vial $(4 \mathrm{~mL})$ open to air then irradiated in a domestic microwave oven (DeLonghi, Perfecto Easy) at $600 \mathrm{~W}$ for $5 \times 1 \mathrm{~min}$ (with intervals of $1 \mathrm{~min}$ for cooling at room temperature). Progress of the reaction was followed by GC-MS analysis. The solid turned quickly to yellow. After washing of the solid with dichloromethane then filtration, the organic layer was washed with saturated $\mathrm{NaHCO}_{3}$ solution, then with brine, dried over $\mathrm{Na}_{2} \mathrm{SO}_{4}$ then concentrated under reduced pressure. The crude product was purified by recrystallization in an ethyl acetateether mixture. A yield of $91 \%$ of diethyl 2,6-dimethyl-4phenyl-3,5-pyridinedicarboxylate $\mathbf{1 5 a}$ was obtained. ${ }^{1} \mathrm{H}$ NMR, IR, and MS data were in accordance with the data previously published (Kumar and Kumar 2010).

Syntheses catalyzed by Eco- $\mathrm{Mn}_{2}$

\section{Controlled oxidation of alcohols into aldehydes}

In a typical procedure, to a suspension of Eco- $\mathrm{Mn}_{2}(4.43 \mathrm{~g}$, amount corresponding to $38.9 \mathrm{mmol}$ of $\mathrm{Mn}$ ) in $20 \mathrm{~mL}$ of EtOAc was added 4-hydroxy-3-methoxybenzyl alcohol 4b $(1.54 \mathrm{~g}, 10 \mathrm{mmol})$ under inert atmosphere. The reaction was monitored by GC-MS. After stirring for $3 \mathrm{~h}$ under reflux, the reaction mixture was filtered and the solid was washed with EtOAc. The solution was concentrated under reduced pressure to give vanillin $\mathbf{5 b}$ with quantitative yield (estimated by GCMS). Vanillin was identified by comparing retention times, IR, and MS spectra with a commercial sample.

\section{Oxidative cleavage of polyol}

To a suspension of Eco- $\mathrm{Mn}_{2}$ (684 mg, amount corresponding to $6.0 \mathrm{mmol}$ of $\mathrm{Mn}$ ) in $20 \mathrm{~mL}$ of acetonitrile was added ethyl 2-methyl-5-((1S,2R,3R)-1,2,3,4-tetrahydroxybutyl)furan-3carboxylate $6(274 \mathrm{mg}, 1.0 \mathrm{mmol})$. After stirring for $5 \mathrm{~h}$ at room temperature (the reaction was monitored by IR), the reaction mixture was filtered through celite and the solid was washed with dichloromethane. The solution was concentrated under reduced pressure, affording ethyl 5-formyl-2methylfuran-3-carboxylate 7 as a white solid, after recrystallization in dichloromethane, in quantitative yield. ${ }^{1} \mathrm{H}$ NMR and IR data were in accordance with those previously reported (Moreno-Vargas et al. 2001).

\section{Direct oxidative iodination of ketones}

To a solution of cyclohexanone $(103.6 \mu \mathrm{L}, 1.0 \mathrm{mmol})$ in methanol $(5 \mathrm{~mL})$ was added sodium iodide $(149.9 \mathrm{mg}, 1.0 \mathrm{mmol})$ and Eco-Mn 2 (228 mg, amount corresponding to $2.0 \mathrm{mmol}$ of $\mathrm{Mn}$ ). After stirring at room temperature for $12 \mathrm{~h}$ (reaction monitored by GC-MS), the mixture was filtered on a pad of celite then washed with a solution of sodium thiosulfate $(2 \mathrm{M})$, dried with $\mathrm{Na}_{2} \mathrm{SO}_{4}$, filtered, and concentrated under reduced pressure. The corresponding 2-iodocyclohexanone was obtained with $64 \%$ yield. ${ }^{1} \mathrm{H}$ NMR and IR data were in accordance with the data previously published (Aizpurua et al. 1985). 
Purification and analysis of products

Flash column chromatography was performed using Chromagel Carlo Erba Reactifs SDS silica 60 A CC 35$70 \mu \mathrm{m}$. Reactions were monitored using Merck Kieselgel 60 F254 aluminum. TLC's were visualized by UV fluorescence $(254 \mathrm{~nm})$ then by immersion in one of the following dyeing reagents: $\mathrm{KMnO}_{4}$, vanillin, ninhydrin, phosphomolybdic acid solution, or phosphotungstic acid solution.

NMR spectra were recorded on a Brüker Avance 300 spectrometer at room temperature, ${ }^{1} \mathrm{H}$ frequency is at $300 \mathrm{MHz},{ }^{13} \mathrm{C}$ frequency is at $75 \mathrm{MHz}$. IR spectra were recorded on a PerkinElmer Spectrum 100 FT-IR spectrometer, in ATR mode. GC-MS analyses were performed on a Shimadzu QP2010SE apparatus, equipped with a $30 \mathrm{~m} \times$ $0.25 \mathrm{~mm} \times 0.25 \mu \mathrm{m}$ ZB-5MSi Guardian column (Phenomenex ${ }^{\circledR}$ ) with hydrogen as carrier gas.

\section{Results and discussion}

Starting from shoots of $G$. exul used in phytoextraction processes on degraded mining sites of New Caledonia, two types of Eco-Mn have been conceived, with different chemical compositions and properties.

Eco- $\mathrm{Mn}_{1}$ : a bivalent Lewis/Brønsted acid catalyst

Eco- $\mathrm{Mn}_{1}$ has been obtained by thermic treatment of leaves of $G$. exul rubiginosa, then acid treatment of the resulting powder, as a polymetallic extract enriched in $\mathrm{Mn}(\mathrm{II})$, with Lewis and Brønsted acid properties.

There are very few mentions of $\mathrm{Mn}$ (II) as Lewis acid catalyst in the literature (Horike et al. 2008; Roy et al. 2010). Mn(II) salts are usually described as weak Lewis acids, which may explain their almost absence in the field of Lewis acid catalysis (Cahiez et al. 2001b). Herein, we describe the preparation, characterization, and use of Eco- $\mathrm{Mn}_{1}$ as a novel bivalent Lewis and Brønsted acid catalyst, derived from Mnhyperaccumulating plants. Unlike classical Mn(II) salts, Eco$\mathrm{Mn}_{1}$ proved to be an efficient acid catalyst due to its original polymetallic composition.

\section{Characterization of Eco-Mn}

ICP-MS analysis of Eco-Mn ${ }_{1}$ ICP-MS analyses of Eco-Mn were performed after dilution of the solid in an aqueous solution of $2.5 \%$ nitric acid (Table 1 ).

The analysis showed that Mn was the major transition metal in the two ecocatalysts. But ecocatalyst derived from G. exul rubiginosa was more concentrated in $\mathrm{Mn}(6.72 \mathrm{wt} \%)$ than ecocatalyst derived from G. exul exul (5.90 wt\%). This observation was consistent with data previously published (Jaffre 1979). A small amount of Ni was observed in the two ecocatalysts. Fe was the second most abundant transition metal in both ecocatalysts, with contents of $1.81 \mathrm{wt} \%$ in Eco- $\mathrm{Mn}_{1}$ from $G$. exul exul and $0.90 \mathrm{wt} \%$ in Eco- $\mathrm{Mn}_{1}$ from G. exul rubiginosa. The quantities of $\mathrm{Mg}, \mathrm{Ca}$, and $\mathrm{Al}$ were similar between the two ecocatalysts. Because of the higher concentration of $\mathrm{Mn}$ in G. exul rubiginosa, we chose to focus on this subspecies to produce Eco- $\mathrm{Mn}_{1}$. The reproducibility of the composition of similar ecocatalysts was studied in a previous article (Escande et al. 2014b), which showed that the levels of transition elements are only slightly variable between samples derived from different plants. The Eco-Mn $\mathrm{Mn}_{1}$ was prepared from several batches of $G$. exul rubiginosa in order to homogenize the content of the transition elements and minimize possible variations in the composition.

$X R D$ analysis of Eco-Mn $n_{1} \mathrm{XRD}$ analysis has been performed in order to investigate the structure of the Eco- $\mathrm{Mn}_{1}$ catalyst (Fig. 4 and Table 2). Two polymetallic chlorides were detected: $\mathrm{CaMg}_{2} \mathrm{Cl}_{6}\left(\mathrm{H}_{2} \mathrm{O}\right)_{12}$ and $\mathrm{KMnCl}_{3}$, which was a masked form of $\mathrm{MnCl}_{2}$. Manganese was thus present in Eco- $\mathrm{Mn}_{1}$ under the oxidation state $\mathrm{Mn}(\mathrm{II})$.

XRD did not reveal the presence of molecules containing Fe or Al, which were detected by the elemental analysis. This was probably due to the non-crystalline nature of these species within the Eco- $\mathrm{Mn}_{1}$ catalyst. As regards the oxidation state of iron in Eco- $\mathrm{Mn}_{1}$, a colorimetric test with ammonium thiocyanate demonstrated that iron was present under the oxidation state Fe(III) in the catalyst (Feigl and Anger 1972).

Infrared characterization of the Lewis and Brønsted acidities of Eco-Mn $n_{1}$ by pyridine adsorption The Lewis acid properties of the Eco- $\mathrm{Mn}_{1}$ were investigated by infrared characterization after pyridine adsorption. Pyridine is widely used for the determination of Lewis acidity of solid acids, by monitoring the bands in the range of $1400-1650 \mathrm{~cm}^{-1}$ arising from its ring vibration modes (Parry 1963; Zaki et al. 2001). Infrared spectra of pyridine adsorbed on Eco- $\mathrm{Mn}_{1}$ were acquired at $25{ }^{\circ} \mathrm{C}$ and $150{ }^{\circ} \mathrm{C}$ in order to distinguish frequencies of physisorbed pyridine from frequencies of pyridine coordinated to Lewis acid sites (Fig. 5).

In Fig. 5, a band at $1443 \mathrm{~cm}^{-1}$ was observed at $25^{\circ} \mathrm{C}$ and shifted to $1446 \mathrm{~cm}^{-1}$ after outgassing at $150{ }^{\circ} \mathrm{C}$. This shift was attributed to the disappearance of physisorbed, weakly bonded pyridine. After outgassing at $150{ }^{\circ} \mathrm{C}$, only strongly bonded pyridine persisted, by coordination to Lewis acid sites (Parry 1963). A similar phenomenon was observed in the range 1570$1640 \mathrm{~cm}^{-1}$. Several frequencies, characteristic of physisorbed pyridine, present at 1573,1592 , and $1600 \mathrm{~cm}^{-1}$ at $25{ }^{\circ} \mathrm{C}$, disappeared after outgassing at $150{ }^{\circ} \mathrm{C}$. In the same range, higher frequencies were recorded after outgassing at elevated temperature $\left(1604\right.$ and $\left.1611 \mathrm{~cm}^{-1}\right)$. The presence of bands in 
Table 1 ICP-MS analysis of Eco-Mn $\mathrm{M}_{1}$ from Grevillea exul exul and Grevillea exul rubiginosa

\begin{tabular}{lllllll}
\hline Ecocatalyst & Mg wt $\%( \pm \mathrm{sd})$ & $\mathrm{Cawt} \%( \pm \mathrm{sd})$ & $\mathrm{Al} w \mathrm{wt} \%( \pm \mathrm{sd})$ & $\mathrm{Mn} w \mathrm{wt} \%( \pm \mathrm{sd})$ & $\mathrm{Fe} w \mathrm{wt} \%( \pm \mathrm{sd})$ & $\mathrm{Ni} w \%( \pm \mathrm{sd})$ \\
\hline Catalyst derived from Grevillea exul exul & $4.68( \pm 0.10)$ & $10.91( \pm 0.20)$ & $0.39( \pm 0.018)$ & $5.90( \pm 0.044)$ & $1.81( \pm 0.0090)$ & $0.12( \pm 0.00046)$ \\
Catalyst derived from Grevillea exul rubiginosa & $5.26( \pm 0.086)$ & $10.44( \pm 0.17)$ & $0.24( \pm 0.015)$ & $6.72( \pm 0.037)$ & $0.90( \pm 0.0075)$ & $0.040( \pm 0.00039)$
\end{tabular}

this range, in spite of heating at high temperature, indicated the presence of strongly bonded pyridine coordinated to Lewis acid sites. It showed the Lewis acidity of Eco- $\mathrm{Mn}_{1}$.

Moreover, the occurrence of the bands at different frequencies in this range may account for the involvement of different types of Lewis acid sites (Zaki et al. 2001). The hypothesis was supported by the previous X-ray data (Table 2), highlighting the presence of different Lewis acids in Eco- $\mathrm{Mn}_{1}$.

In the middle part of the spectra, a band near $1530 \mathrm{~cm}^{-1}$ was weak at $25^{\circ} \mathrm{C}$ but became very intense after degassing at $150{ }^{\circ} \mathrm{C}$. This band has been described as characteristic of the frequency $v_{19 b}$ of the pyridinium ion formed by protonation of pyridine by Brønsted acid (Zaki et al. 2001). The intensity increasing while degassing at $150{ }^{\circ} \mathrm{C}$ was connected to the influence of heating on the kinetics of the pyridine protonation. Eco- $\mathrm{Mn}_{1}$ comprised thus a Brønsted acid character in addition to a Lewis acid character. This Brønsted acidity probably resulted from the hydrolysis of metal chlorides present in Eco- $\mathrm{Mn}_{1}$ (such as $\mathrm{Mn}$ or Fe chlorides) because of the presence of hydrated salts (such as $\mathrm{CaMg}_{2} \mathrm{Cl}_{6}\left(\mathrm{H}_{2} \mathrm{O}\right)_{12}$ ) in the catalyst, as highlighted by XRD experiments (see above). A test on wet $\mathrm{pH}$ indicator paper confirmed the acidity. $\mathrm{A} \mathrm{pH}$ measurement of a clear solution of Eco- $\mathrm{Mn}_{1}$ in water $(12 \mathrm{mg}$ in $20 \mathrm{~mL}$ ) indicated a $\mathrm{pH}$ of 4.5. Such Lewis/Brønsted acid properties suggested that Eco- $\mathrm{Mn}_{1}$ combined novel interesting catalytic properties for organic synthesis. The catalytic potential of Eco- $\mathrm{Mn}_{1}$ was thus explored in a set of Lewis/ Brønsted acid-catalyzed reactions.

\section{Lewis/Brønsted acid catalysis with Eco-Mn ${ }_{1}$}

Formation of alkyl enol ethers by acetalization/dealcoholation from aldehydes Alkyl enols ethers are of great synthetic interest. They are very reactive toward electrophilic moieties, particularly carbonyl groups and are used for the formation of $\mathrm{C}-\mathrm{C}$ bonds in organic synthesis. Compared to their metal

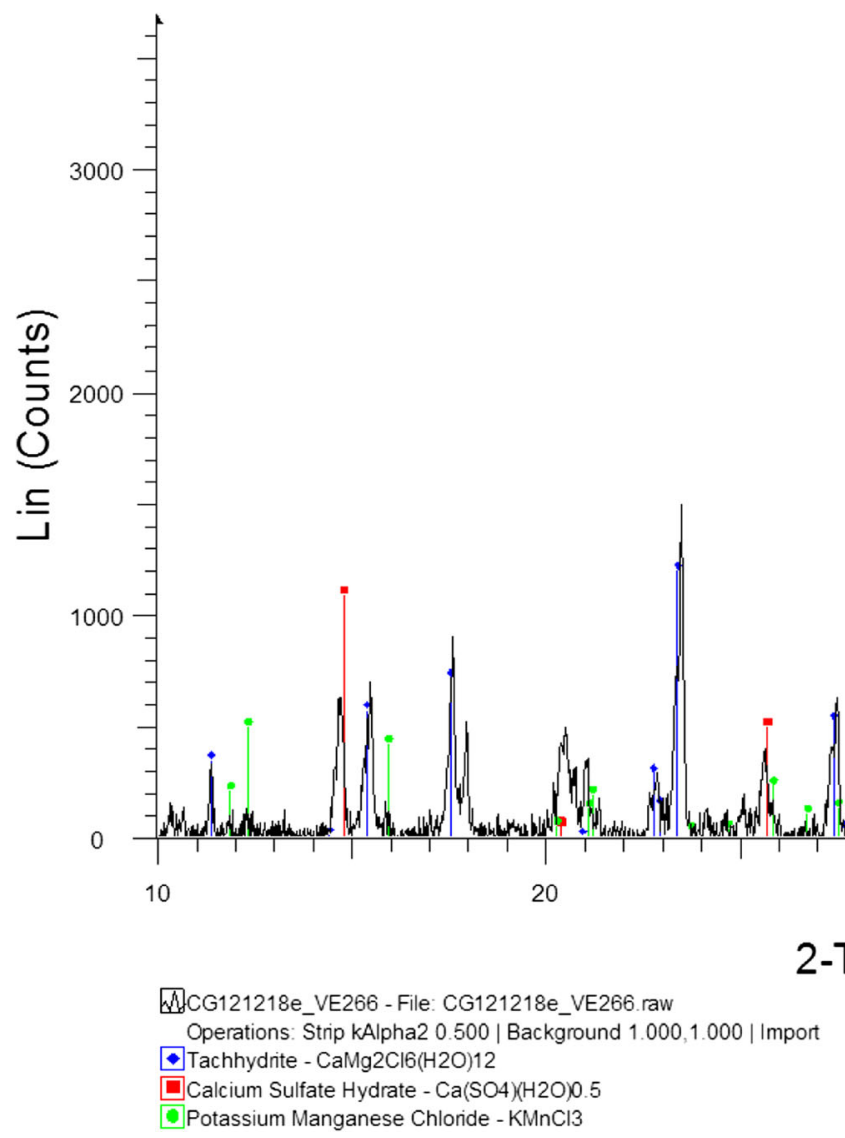

Fig. 4 Characterization of Eco- $\mathrm{Mn}_{1}$ by XRD 
Table 2 Crystalline species present in Eco- $\mathrm{Mn}_{1}$ catalyst and detected by $\mathrm{XRD}$

\begin{tabular}{ll}
\hline Mineral & Formula (simplified) \\
\hline Calcium magnesium chloride hydrate & $\mathrm{CaMg}_{2} \mathrm{Cl}_{6}\left(\mathrm{H}_{2} \mathrm{O}\right)_{12}$ \\
Calcium sulfate hydrate & $\mathrm{CaSO}_{4}\left(\mathrm{H}_{2} \mathrm{O}\right)_{0.5}$ \\
Potassium manganese chloride & $\mathrm{KMnCl}_{3}$ \\
\hline
\end{tabular}

enolate equivalents, alkyl enol ethers are more stable and can often be isolated. Alkyl enol ethers are also widely used in cycloaddition reactions, such as the inverse-electron-demand Diels-Alder reaction (Chavez and Jacobsen 2003; Gademann et al. 2002). An abundant literature is available concerning the preparation of alkyl enol ethers and their synthetic applications (Chan 1991; Gassman et al. 1993; Huisgen 1977). Notable examples of compounds synthesized with alkyl enol ethers include $\beta$-carotene, retinal (vitamin A aldehyde) and its derivatives (Isler et al. 1956; Makin 1976), pyrrolidine alkaloids (Shono et al. 1981), iridoid natural products (Chavez and Jacobsen 2003) and tetrahydroquinoline derivatives (Akiyama et al. 2006), with potential biological activity (Fig. 6).

Classical methods of preparation of alkyl enol ethers involve the use of harsh conditions, such as strong bases (e.g. $n$ butyllithium ( $n$-BuLi), lithium diisopropylamide (LDA), sodium hydride), in organic solvents associated with environmental damages (e.g. tetrahydrofuran, dichloromethane) (Earnshaw et al. 1979; Gassman et al. 1993; Russell and Hegedus 1983). However, it is also possible to synthesize alkyl enol ethers $\mathbf{3}$ starting from aldehydes $\mathbf{1}$, by acetalization with an alcohol under acid catalysis, then elimination of alcohol, under acid or basic catalysis (Rhoads et al. 1970). The elimination step is usually conducted under aggressive Brønsted acids, such as sulfuric acid or $p$-toluenesulfonic acid (Rhoads et al. 1970) or readily hydrolysable Lewis acids such as aluminum chloride (Barbot and Miginiac 1979). This step can also be accomplished under co-catalysis with aluminum chloride and a non-nucleophilic base, such as triethylamine (Barbot and Miginiac 1979). The conditions are contrary to the principles of green chemistry.

Since the infrared characterization of Eco- $\mathrm{Mn}_{1}$ by desorption of pyridine has shown the existence of Lewis and Brønsted acidities for the catalyst, we decided to investigate the efficiency of Eco- $\mathrm{Mn}_{1}$ to catalyze the formation of ethyl enol ether. The reaction was conducted with Eco- $\mathrm{Mn}_{1}$ (amount corresponding to $10 \mathrm{~mol} \%$ of $\mathrm{Mn}$ ) in anhydrous ethanol at $80^{\circ} \mathrm{C}$, with aliphatic aldehydes as model substrates (Scheme 1 and Table 3).

Aliphatic acetals $\mathbf{2 a}$ and $\mathbf{2 b}$ were obtained in good yields (77-96 \%) after $5 \mathrm{~h}$. It is interesting to note that when the reaction was conducted on ketones, no trace of ketal was detected, the starting ketone remaining unchanged. This is in accordance with the less electrophilic character of ketones in comparison with aldehydes. The alcohol elimination of the resulting acetals led to the formation of the corresponding ethyl enol ethers 3a, 3b in good yields (82-89\%). The diastereomeric ratio of $E / Z$ were similar to those previously reported (Barbot and Miginiac 1979), the more stable $Z$ diastereomer being slightly preponderant.

When citronellal was used as the aldehyde substrate, enol ether $\mathbf{3 c}$ was obtained directly and in good yield (96\%) after $5 \mathrm{~h}$. It is interesting to note that no trace of acetal was detected. The elimination of the intermediate acetal has been facilitated by Eco- $\mathrm{Mn}_{1}$. According to IR studies above mentioned, Eco- $\mathrm{Mn}_{1}$ presented both Lewis and Brønsted acid characters. This induced a great affinity toward O-ethyl groups and promoted the elimination step. Eco- $\mathrm{Mn}_{1}$ thus proved to be a valuable alternative to classical acid catalysts used for the synthesis of ethyl enol ethers, avoiding the use of strong acid catalysts or sensitive reagents. As Eco- $\mathrm{Mn}_{1}$ was partially soluble in the reaction medium, its incorporation into a solid support could be the subject of further study, enabling its recovery by filtration and possibly its recycling, at the end of the reaction.
Fig. 5 IR spectra of pyridine adsorbed on $\mathrm{Eco}-\mathrm{Mn}_{1}$ recorded following outgassing at the indicated temperatures

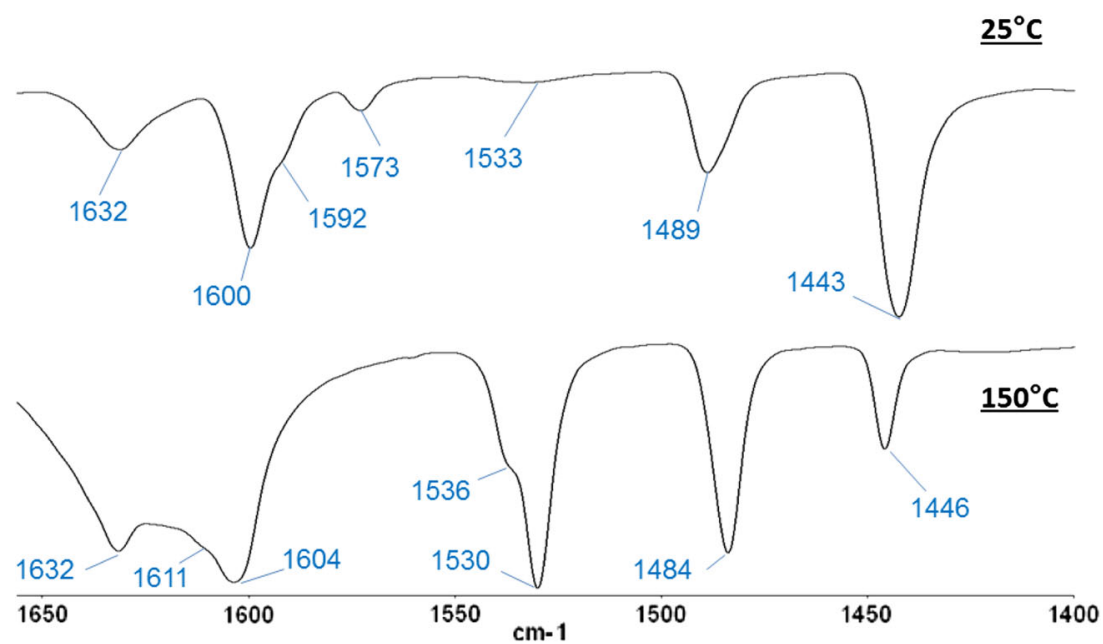


Fig. 6 Examples of compounds synthesized with alkyl enol ethers

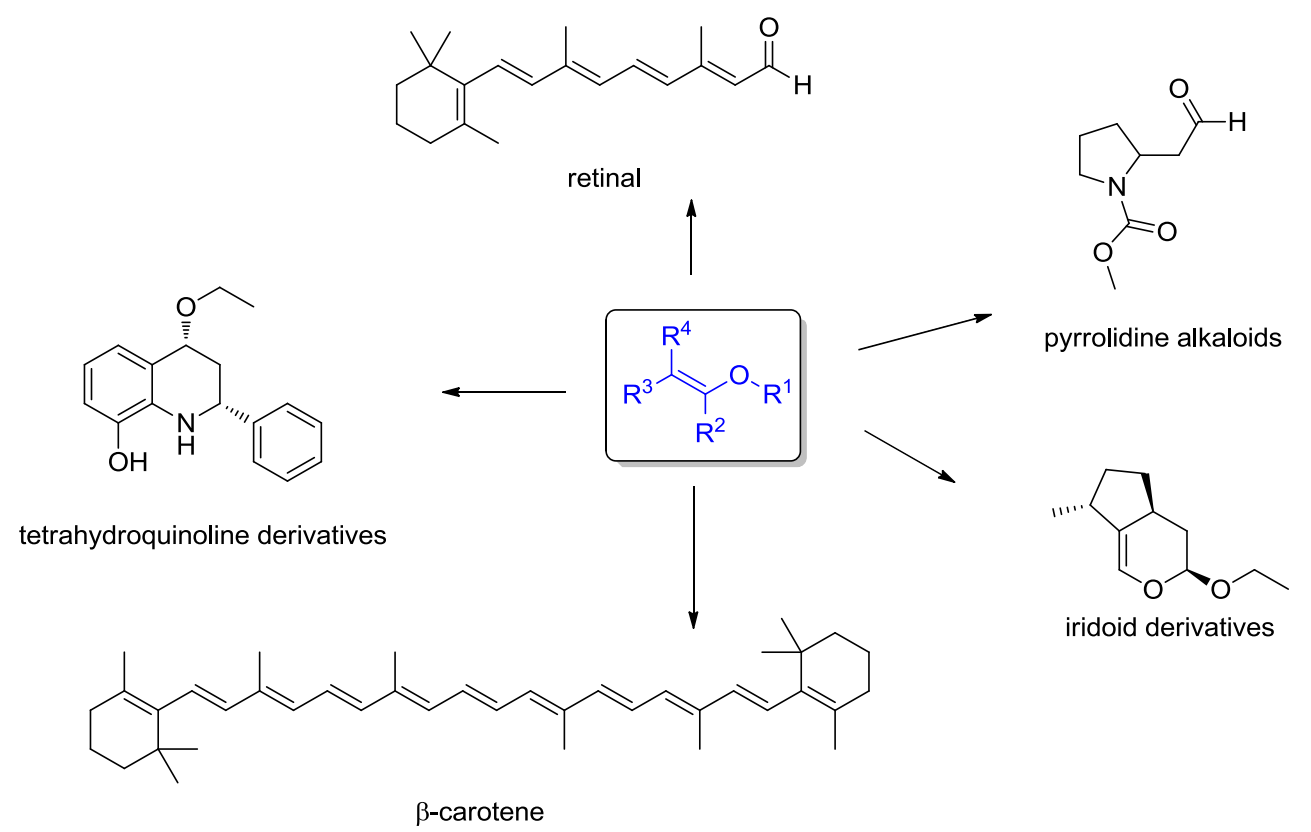

Carbonyl-ene cyclization of citronellal into isopulegol The ene-cyclization of the monoterpene (+)-citronellal into (-)isopulegol is the main step of the best industrial process for $(-)$-menthol production, which is worldwide one of the most important flavor chemicals (Clark 2007; Lawrence and Hopp 2006). (-)-Isopulegol is also used in perfumery in various blossom compositions as geranium notes.

As the skeleton of the (-)-isopulegol molecule has two new stereogenic centers compared to (+)-citronellal, this intramolecular carbonyl-ene reaction can lead to four diastereomers namely (-)-isopulegol, (+)-iso-isopulegol, (+)-neo-isopulegol, and $(+)$-neoiso-isopulegol (Fiege 2012). Among the four pairs of optical menthol enantiomers, only (-)-menthol exhibits the characteristic peppermint odor and also exerts a cooling effect. As only (-)-isopulegol affords the correct (-)-menthol configuration during its selective hydrogenation, its synthesis from (+ )-citronellal requires a high diastereoselectivity (ds).

It is known that the isomerization of (+)-citronellal occurs in the presence of various homogeneous and heterogeneous acid catalysts and the most selective catalysts toward the formation of (-)-isopulegol are Lewis acids (Imachi et al. 2007). Brønsted acidity enhances the rate of isomerization of citronellal but is less selective toward the formation of (-)isopulegol (Da Silva et al. 2004; Kropp et al. 1995). The selectivity of this cyclization is directly related to the strength of the Lewis acid metal centers. It depends also on solvent and reaction temperature.

Scheme 1 General concept of acetalization/elimination of

aldehydes catalyzed by Eco- $\mathrm{Mn}_{1}$
According to the hard and soft acids bases (HSAB) theory (Ho 1975), $\mathrm{Mn}^{2+}$ is a hard Lewis acid and can advantageously replace $\mathrm{AlCl}_{3}, \mathrm{FeCl}_{3}$, and $\mathrm{BF}_{3}$ in a number of reactions such as the ene-reaction. However, its use is limited by a low reactivity. The polymetallic composition of Eco-Mn $\mathrm{Mn}_{1}$ and the presence of cations such as $\mathrm{Fe}^{3+}$, and $\mathrm{Al}^{3+}$ could exalt the classical reactivity of $\mathrm{Mn}^{2+}$. Thus, the ecocatalyst could provide an interest in the catalysis of the carbonyl-ene reaction. We decided to evaluate the efficiency of Eco- $\mathrm{Mn}_{1}$ as catalyst for the reaction.

As described in the literature (Imachi et al. 2007), the best selectivity was obtained in dichloromethane (e.g. rather than toluene). Eco- $\mathrm{Mn}_{1}$ catalyzed efficiently the reaction in dichloromethane, giving $95 \%$ yield and a selectivity of $90 \%$ toward (-)-isopulegol, with only $2 \mathrm{~mol} \%$ of $\mathrm{Mn}$, in very short reaction time (0.5 h) (Fig. 7).

The selectivity toward the isomer of interest, (-)isopulegol, is higher with Eco- $\mathrm{Mn}_{1}$ than those obtained with others transition metal chlorides such as: $\mathrm{ZnCl}_{2}, \mathrm{FeCl}_{3}, \mathrm{TiCl}_{4}$, $\mathrm{SnCl}_{4}, \mathrm{SbCl}_{3}$ (Nakatani and Kawashima 1978) $\mathrm{InCl}_{3}, \mathrm{NbCl}_{5}$, $\mathrm{TaCl}_{5}$ (Andrade et al. 2004), and $\mathrm{CuCl}_{2}$ (Alaerts et al. 2006).

The rate of $90 \%$ is important, because it allows avoiding the purification of the mixture for its industrial utilization. This result shows that Eco- $\mathrm{Mn}_{1}$ is an efficient catalyst for the carbonyl-ene reaction and could replace advantageously classical Lewis acids. Moreover, as Eco- $\mathrm{Mn}_{1}$ proved to be insoluble in the reaction medium, its recovery by simple filtration then washing was possible. After drying under

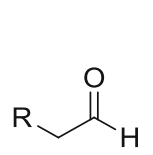

1

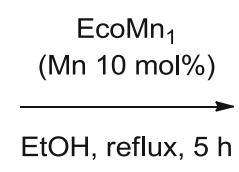

EcoMn $_{1}$

EtOH, reflux, $5 \mathrm{~h}$

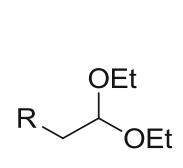

2

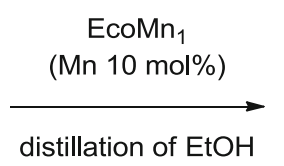

$R \backslash m O E t$ 
Table 3 Acetalization/elimination of aldehydes catalyzed by Eco- $\mathrm{Mn}_{1}$

Entry $^{\mathrm{a}}$ Aldehyde

\footnotetext{
${ }^{a}$ Reaction conditions: aldehyde (1.0 mmol), Eco- $\mathrm{Mn}_{1}(82 \mathrm{mg}$, amount corresponding to $10 \mathrm{~mol} \%$ of $\mathrm{Mn})$, anhydrous ethanol $(3 \mathrm{~mL}), 80{ }^{\circ} \mathrm{C}, 5 \mathrm{~h}$

${ }^{\mathrm{b}}$ Yield was determined by GC-MS with biphenyl as internal standard

${ }^{\mathrm{c}}$ Proportions of diastereomers were determined by GC-MS, according to Barbot and Miginiac (Barbot and Miginiac 1979)

${ }^{\mathrm{d}}$ The GC separation of diastereomers was insufficient to determine their proportions
}

reduced pressure, the recycled Eco- $\mathrm{Mn}_{1}$ could be reused in the reaction without significant loss of activity.

Eco- $\mathrm{Mn}_{2}$ : a versatile biosourced oxidation reagent

As described in the previous sections, the manganesehyperaccumulating plant $G$. exul rubiginosa is a valuable vegetal source of manganese. Eco-Mn $\mathrm{M}_{1}$ proved to be an effective Lewis acid catalyst, because its polymetallic composition increased its catalytic properties. In this section, we consider G. exul rubiginosa for preparing a Mn(IV)-derived biosourced oxidation reagent, named Eco- $\mathrm{Mn}_{2}$.

Oxidation of organic compounds by $\mathrm{Mn}(\mathrm{IV})$ species, mainly under the form of manganese dioxide, has long been known in organic synthesis (Cahiez et al. 2001a; Fatiadi 1976a, b; Fatiadi 1986; Taylor et al. 2005). $\mathrm{MnO}_{2}$ displays several advantages as a green oxidation reagent: this compound is non-toxic, widely available, and cheap. However, the oxidizing capacity of $\mathrm{MnO}_{2}$ is modest and it is seldom used synthetically. $\mathrm{MnO}_{2}$ needs to be prepared under active form for displaying its oxidizing activity. Moreover, even under the active form, oxidation reactions with $\mathrm{MnO}_{2}$ require a large excess of oxidant (typically 10 equivalents). The development of simple and sustainable methods of preparation of active $\mathrm{Mn}(\mathrm{IV})$ are thus useful.
With Mn(II) species from G. exul rubiginosa on hand, we were able to develop a novel method of preparation of active $\mathrm{Mn}(\mathrm{IV})$ by the mean of dioxygen from air, yielding Eco- $\mathrm{Mn}_{2}$ as an efficient and biosourced oxidation reagent. The preparation of Eco- $\mathrm{Mn}_{2}$ was based on the oxidation by dioxygen from air at $\mathrm{pH} 8$, of $\mathrm{Mn}$ (II) from Eco- $\mathrm{Mn}_{1}$ into $\mathrm{Mn}_{2} \mathrm{O}_{3}$ $(\mathrm{Mn}(\mathrm{III}))$ and $\mathrm{Mn}_{3} \mathrm{O}_{4}(\mathrm{Mn}(\mathrm{II}, \mathrm{III}))$, then into $\mathrm{Mn}(\mathrm{IV})$ and $\mathrm{Mn}$ (II) by disproportionation, after acidification at $\mathrm{pH} \mathrm{3,} \mathrm{ac-}$ cording to the following equations:

$\mathrm{Mn}_{3} \mathrm{O}_{4}+2 \mathrm{H}^{+} \rightarrow \mathrm{Mn}^{2+}+\mathrm{Mn}_{2} \mathrm{O}_{3}+\mathrm{H}_{2} \mathrm{O}$

$\mathrm{Mn}_{2} \mathrm{O}_{3}+2 \mathrm{H}^{+} \rightarrow \mathrm{Mn}^{2+}+\mathrm{MnO}_{2}+\mathrm{H}_{2} \mathrm{O}$

\section{Characterization of Eco- $\mathrm{Mn}_{2}$}

In order to use Eco- $\mathrm{Mn}_{2}$ in organic synthesis, its elemental composition has been investigated by ICP-MS, after dissolving the solid in aqua regia (concentrated nitric acid/hydrochloric acid, 1:3) then dilution with an aqueous solution of $2.5 \%$ nitric acid (Table 4 ).

The analysis shows that $\mathrm{Mn}$ is by far the major metallic element present in Eco- $\mathrm{Mn}_{2}$, as its content reaches $48.22 \mathrm{wt} \%$. 
Fig. 7 Carbonyl-ene cyclization of (+)-citronellal into isopulegol under catalysis with Eco- $\mathrm{Mn}_{1}$

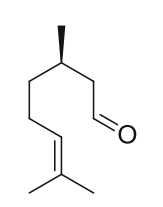

$(R)-(+)$-citronellal
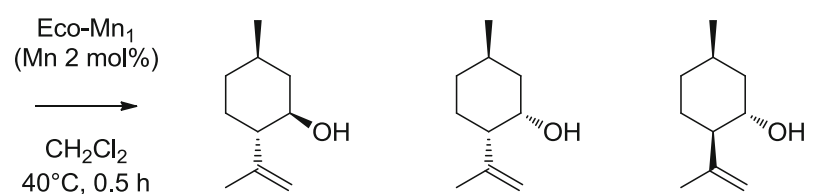

(R)-(-)-isopulegol

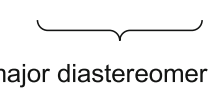

$(R)-(+)$-neo-isopulegol $(R)-(+)$-iso-isopulegol

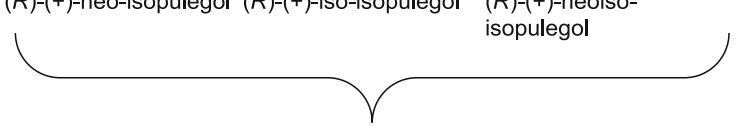

+3 minor diastereomers

selectivity (\%):

8

I

2

traces
The value can be compared to the $\mathrm{Mn}$ content in pure $\mathrm{MnO}_{2}$, which is $63.19 \mathrm{wt} \%$. The difference between the two values is explained by the presence of $\mathrm{Fe}$ in significant proportions $(6.79 \mathrm{wt} \%)$ and by traces of other metallic elements, mainly $\mathrm{Ca}(2.85 \mathrm{wt} \%)$. Because of the acidification by hydrochloric acid, $\mathrm{Cl}$ is also present under the form of metallic chlorides, but the amount of this element could not be established by the analysis. The percent of recovery of each element from Eco$\mathrm{Mn}_{1}$ has been calculated by using the data in Table 1, with the masses of the starting Eco- $\mathrm{Mn}_{1}(50 \mathrm{mg})$ and of the resulting Eco- $\mathrm{Mn}_{2}(5.5 \mathrm{mg})$. These values show that $\mathrm{Mn}, \mathrm{Fe}$, and $\mathrm{Ni}$ were recovered efficiently (78.93-96.25\% recovery), whereas high proportions of $\mathrm{Mg}, \mathrm{Ca}$, and $\mathrm{Al}$ were lost during the preparation of Eco- $\mathrm{Mn}_{2}$, probably during the washing with water (1.48-35.75\% recovery). The resulting Eco- $\mathrm{Mn}_{2}$ is thus highly enriched in $\mathrm{Mn}$ (under the form of $\mathrm{MnO}_{2}$ and $\mathrm{Mn}$ (II) chlorides) and $\mathrm{Fe}$ (under the form of $\mathrm{Fe}(\mathrm{III})$ chlorides). It should be noted that the $\mathrm{Mn} / \mathrm{Fe}$ ratio in Eco- $\mathrm{Mn}_{2}$ is almost the same as for Eco- $\mathrm{Mn}_{1}\left(\mathrm{Mn} / \mathrm{Fe}, 7.47\right.$ in Eco- $\mathrm{Mn}_{1} ; 7.10$ in Eco- $\mathrm{Mn}_{2}$ ).

The preparation of Eco- $\mathrm{Mn}_{2}$ by disproportionation of $\mathrm{Mn}_{2} \mathrm{O}_{3}(\mathrm{Mn}(\mathrm{III}))$ and $\mathrm{Mn}_{3} \mathrm{O}_{4}(\mathrm{Mn}(\mathrm{II}, \mathrm{III})$ ) produced $\mathrm{Mn}(\mathrm{IV})$ and $\mathrm{Mn}$ (II) species (see Eqs. 1 and 2). Attempts to determine the $\mathrm{Mn}(\mathrm{II}) / \mathrm{Mn}(\mathrm{IV})$ ratio by X-ray photoelectron spectroscopy (XPS) were unsuccessful, because of the complexity of the observed signals. We thus made an estimation of the $\mathrm{Mn}$ (II)/ $\mathrm{Mn}(\mathrm{IV})$ ratio based on the two extreme cases: if $\mathrm{Mn}_{3} \mathrm{O}_{4}$ ( $\mathrm{Mn}(\mathrm{II}, \mathrm{III})$ ) is the major oxide formed by oxidation with air, the $\mathrm{Mn}(\mathrm{II}) / \mathrm{Mn}$ (IV) ratio (after disproportionation) is equal to 2; if $\mathrm{Mn}_{2} \mathrm{O}_{3}(\mathrm{Mn}(\mathrm{III}))$ is the major oxide formed by oxidation, then the $\mathrm{Mn}(\mathrm{II}) / \mathrm{Mn}(\mathrm{IV})$ ratio (after disproportionation) is equal to 1 . The actual $\mathrm{Mn}(\mathrm{II}) / \mathrm{Mn}(\mathrm{IV})$ ratio is therefore comprised between these two extreme values. Supplementary spectroscopic study of Eco- $\mathrm{Mn}_{2}$, which proved to be a quite complex material, is under progress in our laboratory.

Considering this composition, Eco- $\mathrm{Mn}_{2}$ should prove interesting properties in oxidation reactions involving $\mathrm{Mn}(\mathrm{IV})$ as the oxidizing species, with assistance of $\mathrm{Mn}$ (II) and $\mathrm{Fe}$ (III) chlorides as Lewis acids and as potential sources of Brønsted acidity (by hydrolysis in presence of hydrated salts, as observed with Eco- $\left.\mathrm{Mn}_{1}\right)$. Because of a specific IR absorption of
Eco- $\mathrm{Mn}_{2}$ without pyridine, between 1500 and $1630 \mathrm{~cm}^{-1}$, the characterization of Eco- $\mathrm{Mn}_{2}$ by pyridine adsorption could not provide information. Only a slight band at $1445 \mathrm{~cm}^{-1}$ was observed as a proof of the Lewis acidity of Eco- $\mathrm{Mn}_{2}$. A slight Brønsted acidity was indicated by a positive test of Eco- $\mathrm{Mn}_{2}$ on wet $\mathrm{pH}$ indicator paper. $\mathrm{pH}$ measurement of a suspension of Eco- $\mathrm{Mn}_{2}$ (10 mg in $20 \mathrm{~mL}$ of water) indicated a value of 6.5. In addition, the acidity of Eco- $\mathrm{Mn}_{2}$ was clearly indicated by the results obtained in organic reactions detailed below.

Unlike Eco- $\mathrm{Mn}_{1}$, Eco- $\mathrm{Mn}_{2}$ could not be characterized by $\mathrm{XRD}$ analysis, because of the amorphous structure of the solid obtained. This is in accordance with previously described observations about the form of $\mathrm{MnO}_{2}$ prepared by precipitation procedures, as most of the methods led to amorphous solids which could not be characterized by XRD (Fatiadi 1986).

\section{Examples of Eco-Mnn -promoted oxidations}

Oxidation of allylic and benzylic alcohols into aldehydes To start our investigations on the oxidation of organic substrates with Eco- $\mathrm{Mn}_{2}$, we selected the oxidation of benzyl alcohol 4a into benzaldehyde 5a as a model reaction (Scheme 2).

Oxidation of benzyl alcohol to benzaldehyde is an important chemical reaction, as benzaldehyde is one of the most industrially useful compounds. Commercially, the oxidation of benzyl alcohol in liquid phase is a common route for the manufacture of benzaldehyde. Numerous oxidizing agents are available to effect this key reaction, as it is an important transformation in synthetic organic chemistry. Although several stoichiometric reagents based on activated dimethyl sulfoxide (Swern oxidation) (Lee 1991), hypervalent iodine compounds (Dess-Martin periodinane) (Dess and Martin 1983), and reactive oxo-metal compounds (Ley and Madin 1991) $\left(\mathrm{MnO}_{2}\right.$ and pyridinium chlorochromate) have been developed, the search for new catalytic procedures for selective oxidations of benzylic or allyllic alcohols remains an area of intensive interest. Indeed, in spite of their efficiency, the drawback of such oxidants in the perspective of their use in multistage organic synthesis is their lack of selectivity. For instance, over-oxidation of aldehydes into carboxylic acids 
Table 4 Elemental composition of Eco- $\mathrm{Mn}_{2}$ and recovery of the elements from Eco- $\mathrm{Mn}_{1}$

\begin{tabular}{|c|c|c|c|c|c|c|}
\hline Ecocatalyst & $\mathrm{Mg} \mathrm{wt} \%( \pm \mathrm{sd})$ & Ca wt $\%( \pm$ sd $)$ & $\mathrm{Al} w \mathrm{t} \%( \pm \mathrm{sd})$ & $\mathrm{Mn} w \mathrm{t} \%( \pm \mathrm{sd})$ & $\mathrm{Fe} w \mathrm{t} \%( \pm \mathrm{sd})$ & $\mathrm{Ni} w \mathrm{t} \%( \pm \mathrm{sd})$ \\
\hline Eco-Mn $\mathrm{Mn}_{2}$ from Grevillea exul rubiginosa & $0.71( \pm 0.0019)$ & $2.85( \pm 0.0015)$ & $0.78( \pm 0.0028)$ & $48.22( \pm 0.0012)$ & $6.79( \pm 0.0024)$ & $0.35( \pm 0.0027)$ \\
\hline $\begin{array}{l}\text { Percent of recovery of the element from } \\
\text { Eco-Mn } \mathrm{Mn}_{1} \text { (in \%) }\end{array}$ & 1.48 & 3.00 & 35.75 & 78.93 & 82.99 & 96.25 \\
\hline
\end{tabular}

and degradation of unsaturated substrates are often unavoidable side reactions. Furthermore, high temperatures and presence of strong acids or bases required by some oxidation procedures often leads to detrimental side reactions.

As described in Table 5, entry 1, the plant-derived Eco- $\mathrm{Mn}_{2}$ allowed the quantitative formation of benzaldehyde with less than 4 molar equivalents of Mn. The amounts of Mn species were small compared to the classical conditions (typically, 10 equivalents (Cahiez et al. 2001a)). This example illustrates the advantage of using manganese-hyperaccumulating species to replace the commercial oxidizing reagent $\mathrm{MnO}_{2}$.

Different explanations could explain the result. First, the high oxidizing activity of Eco- $\mathrm{Mn}_{2}$ may result to the controlled disproportionation of $\mathrm{Mn}_{2} \mathrm{O}_{3}$ and $\mathrm{Mn}_{3} \mathrm{O}_{4}$ into active $\mathrm{MnO}_{2}$, realized during the preparation of Eco- $\mathrm{Mn}_{2}$. Secondly, the original and polymetallic composition of the medium (particularly $\mathrm{Fe}(\mathrm{III})$ species) may exalt the oxidizing power of $\mathrm{Mn}(\mathrm{IV})$ while controlling the reaction to the expected aldehyde stage. In order to learn more about these results, it was of interest to study the reactivity of the mixture of commercial $\mathrm{MnO}_{2}$ and $\mathrm{FeCl}_{3}$. In the previous conditions, only $20 \%$ of benzaldehyde was obtained (Table 5 , entry 3 ). This result clearly indicated that the combination of $\mathrm{Mn}(\mathrm{IV})$ and $\mathrm{Fe}$ (III) cannot explain the observed yield. It may be concluded to a synergetic effect between the present species. At the end of the reaction, a black solid of similar aspect than the starting Eco- $\mathrm{Mn}_{2}$ was recovered by filtration. After washing and drying, a reaction was attempted with this recycled Eco- $\mathrm{Mn}_{2}$. Almost no oxidation of the starting alcohol was observed, which is in accordance with the reduction of $\mathrm{Mn}(\mathrm{IV})$ during the first run, probably into $\mathrm{Mn}(\mathrm{II})$. This could constitute a complementary way to prepare a new catalyst, highly enriched in $\mathrm{Mn}(\mathrm{II})$, by reduction of Eco- $\mathrm{Mn}_{2}$ whose content in $\mathrm{Ca}, \mathrm{Mg}$, and $\mathrm{Al}$ is much lower than in Eco- $\mathrm{Mn}_{1}$. Other reducing reagents, compliant with green chemistry principles, such as $\mathrm{FeCl}_{2}$ could also be envisioned for the reduction of $\mathrm{Mn}(\mathrm{IV})$ of Eco- $\mathrm{Mn}_{2}$ into $\mathrm{Mn}(\mathrm{II})$.

The absence of benzoic acid among the reaction products constituted a proof to assess the mildness of this oxidation procedure. This advantage was illustrated with the oxidation of 4-hydroxy-3-methoxybenzyl alcohol (vanillic alcohol). The reaction was also very effective with Eco- $\mathrm{Mn}_{2}$ (Table 5, entry 4). It led to vanillin in a remarkably simple and efficient green process. This result is of great industrial importance, as vanillin is the most consumed flavor in the world. This synthesis is completely bio-based: the precursor alcohol is a natural and abundant substance in a number of plant species such as Picea sitchensis (Pinaceae) (Buckingham 1994); the oxidant is completely natural, as prepared from plant extract. Such synthesized vanillin can be described as natural vanillin flavor (Stanzione et al. 2012).

This oxidation reaction is easily transposable to the controlled oxidation of allylic alcohols under similar conditions. This possibility is illustrated with the example of geraniol which leads to geranial (trans-citral) (Table 5, entry 5) which faces high demand for its lemon scent in the food industry or as an important intermediate for the production of perfumes, fragrances, and pharmaceuticals (Hoelderich and Kollmer 2000) (Scheme 3).

Encouraged by these results, the oxidation of the polyol 6 was carried out with the aim to study the regioselectivity of the reaction. In view of its multifunctionality, the derivative $\mathbf{6}$ was an interesting model substrate. The presence of polyol, the cyclic furan, and the carboxylic ester moiety were an opportunity to know the behavior of Eco- $\mathrm{Mn}_{2}$ (Scheme 4).

The reaction was followed by ${ }^{1} \mathrm{H}$ NMR. Surprisingly, we observed the presence of a characteristic singlet at 9.7 ppm by ${ }^{1} \mathrm{H}$ NMR. After work-up, the conjugated aldehyde 7 was identified.

The quantitative formation of 7 was attained with 6 equivalents of $\mathrm{Mn}$ from Eco- $\mathrm{Mn}_{2}$, and $5 \mathrm{~h}$ of agitation at room temperature in acetonitrile. We could conclude that Eco- $\mathrm{Mn}_{2}$ promoted the oxidative cleavage of the polyol 6 in the benzylic position. The reaction showed no competing side reactions, which confirmed the excellent regioselectivity of the cleavage. We found that the control of the oxidation conditions was optimal, since the aldehyde 7 was not oxidized further.

The yield of the reaction is markedly higher with Eco- $\mathrm{Mn}_{2}$ in comparison with $\mathrm{Ce}(\mathrm{IV})$ reagents, which needed a large excess of oxidant (11 equivalents, $48 \%$ yield) (Moreno-Vargas et al. 2001).

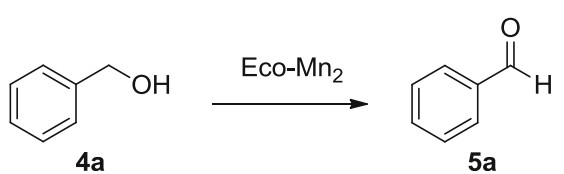

Scheme 2 Controlled oxidation of benzylic alcohol with Eco- $\mathrm{Mn}_{2}$ into benzaldehyde 
Table 5 Oxidation of alcohols by Eco- $\mathrm{Mn}_{2}$

\begin{tabular}{|c|c|c|c|c|}
\hline Entry & Alcohol & $\begin{array}{l}\text { Oxidizing } \\
\text { reagent }^{\mathrm{a}}\end{array}$ & Product & Yield $(\%)^{b}$ \\
\hline 1 & $4 a$ & Eco- $\mathrm{Mn}_{2}$ & $5 a$ & 100 \\
\hline 2 & $4 a$ & $\mathrm{MnO}_{2}$ & $5 a$ & traces \\
\hline 3 & $4 a$ & $\mathrm{MnO}_{2}+\mathrm{FeCl}_{3}{ }^{\mathrm{c}}$ & $5 a$ & 20 \\
\hline 4 & $\begin{array}{l}\text { OMe } \\
\mathbf{4 b}\end{array}$ & Eco- $-\mathrm{Mn}_{2}$ & $\begin{array}{l}\text { OMe } \\
\mathbf{5 b}\end{array}$ & 100 \\
\hline 5 & $4 c$ & Eco- $\mathrm{Mn}_{2}$ & $5 c$ & $100^{\mathrm{d}}$ \\
\hline
\end{tabular}

The oxidative cleavage of vicinal polyols is a reaction of great synthetic importance, mainly applied to the fission of 1,2 diols (glycols) (Perlin 2006). The nature of the conventional reagents illustrated the importance of the result obtained with Eco- $-\mathrm{Mn}_{2}$. Periodic acid and its salts and lead tetraacetate are the most commonly used reagents for the oxidative cleavage of glycols, but several others have been described and reviewed. The following are examples of reagents used for the transformation: $\mathrm{NaBiO}_{3}, \mathrm{Ce}(\mathrm{IV})$ reagents, sodium and calcium hypochlorite, $\mathrm{Cr}(\mathrm{VI}), \mathrm{Co}(\mathrm{II})$, or $\mathrm{V}(\mathrm{IV})$ reagents, and $\mathrm{N}$-iodosuccinimide (Shing 1991). Although these reagents are

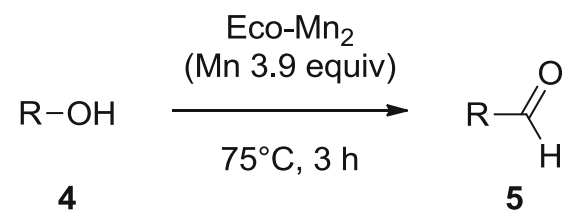

Scheme 3 General concept of the oxidation of alcohols by Eco- $\mathrm{Mn}_{2}$ effective in the reaction, most of them are highly toxic or unstable and generate problematic wastes, excluding their use in a sustainable perspective. More recently, methodologies implying the use of $\mathrm{O}_{2}$ as oxidizing reagent have been developed, under catalysis with ruthenium (Takezawa et al. 1999), palladium (Wang and Jiang 2010), or cobalt species (Iwahama et al. 2000). Although these methods represent valuable green improvements in oxidative cleavage of glycols, the catalysts involved are based on rare and expensive metals, limiting their use. Among the reagents described for the reaction, one could
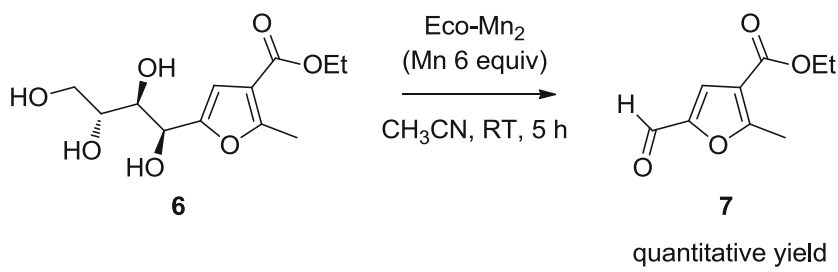

Scheme 4 Oxidation of polyhydroxyalkyl furan 6 by Eco- $-\mathrm{Mn}_{2}$ 


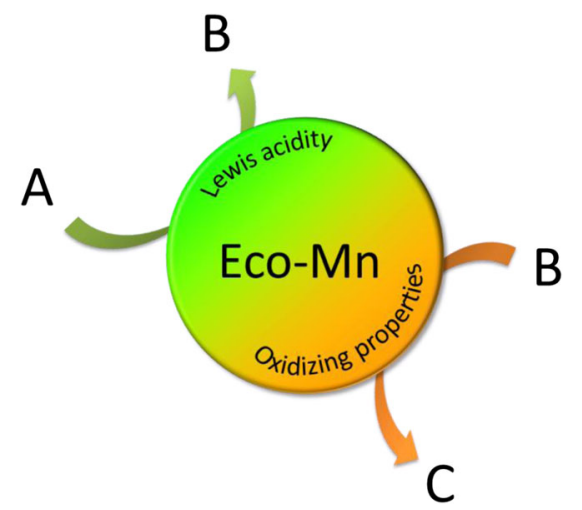

Fig. 8 General concept of sequential tandem oxidations catalyzed by Eco-Mn

also notice a brief mention of $\mathrm{MnO}_{2}$, apparently untapped later in spite of its high efficiency (Ohloff and Giersch 1973).

As even with activated commercial $\mathrm{MnO}_{2}$ a large excess of reagent is needed (typically more than 30 equivalents (Ohloff and Giersch 1973)), we made the hypothesis that the superior activity of Eco- $\mathrm{Mn}_{2}$ is due to the presence of Lewis acids (Mn(II) and $\mathrm{Fe}$ (III) chlorides), promoting the formation then the opening of the cyclic intermediate probably involved in the mechanism, as previously reported for sodium periodate or lead tetraacetate (Perlin 2006). The involvement of such cyclic intermediate is supported by the previous experimental conclusions made by Ohloff and Giersch, when they described that only 1,2-cis-diols or flexible 1,2-trans-diols can be cleaved by $\mathrm{MnO}_{2}($ Ohloff and Giersch 1973). Only one study has mentioned the use of $\mathrm{MnO}_{2}$ in the reaction since the work of Ohloff and Giersch, but without mechanistic considerations on the oxidative cleavage (Outram et al. 2002). Because of this almost-absence in the literature of experimental data on the mechanism of the $\mathrm{MnO}_{2}$-oxidative cleavage of glycol, this could be the object of a further study.

The oxidative cleavage of polyhydroxyalkyl furan $\mathbf{6}$ into furanic aldehyde 7 could be an interesting way to produce functionalized furfural-derived compounds, with new functionalities compared to the widely studied furfural (Serrano-
Ruiz et al. 2011) and 5-hydroxymethylfurfural (Rosatella et al. 2011).

Eco-Mn: Janus catalysts for sequential tandem oxidations

Sequential tandem oxidations can be described as multistep processes, in which transformation of the substrate occurs via two (or more) mechanistically distinct processes, one of them being an oxidation, thanks to the action of species already present at the beginning of the reaction (Fogg and Dos Santos 2004). Because tandem processes reduce the number of operations and allow reactive intermediates to be prepared and reacted in situ, avoiding their isolation and often preventing safety problems, such processes are consistent with the green chemistry principles (Anastas and Warner 1998).

Transition elements are frequently involved in tandem oxidation processes, as they often combine different chemical properties acting in the different steps of the sequential reaction (Davi and Lebel 2009; Guo et al. 2009; Wang et al. 2010; Yip et al. 2006). Among these elements, manganese is the object of a number of publications devoted to tandem oxidations, mainly with Mn(III) (Li et al. 2011; Snider 1996; Snider and O'Hare 2001; Tanyeli et al. 2002; Tanyeli and Sezen 2000) and Mn(IV) (McAllister et al. 2006; Quesada et al. 2006; Quesada and Taylor 2005; Taylor et al. 2005).

In the previous sections, we have shown that Eco- $\mathrm{Mn}_{2}$ demonstrates both oxidizing properties and Lewis/Brønsted acidity. We decided thus to investigate the potential of Eco$\mathrm{Mn}_{2}$ in sequential tandem oxidations, as a "Janus catalyst" (a previously described type of material with two different catalytic properties, from the two-faced Roman god Janus (Cobo et al. 2012; Lv et al. 2012)). The reactions we considered involve two different steps, one being conducted under Lewis or Brønsted acid catalysis and the other one consisting in an oxidation. Such reactions are usually performed with two different species: a catalyst and an oxidizing reagent. Being able to combine these two activities in one unique material offers great advantages in a sustainable perspective, with
Scheme 5 Direct oxidative iodination of ketones with $\mathrm{NaI} /$ $\mathrm{Eco}-\mathrm{Mn}_{2}$

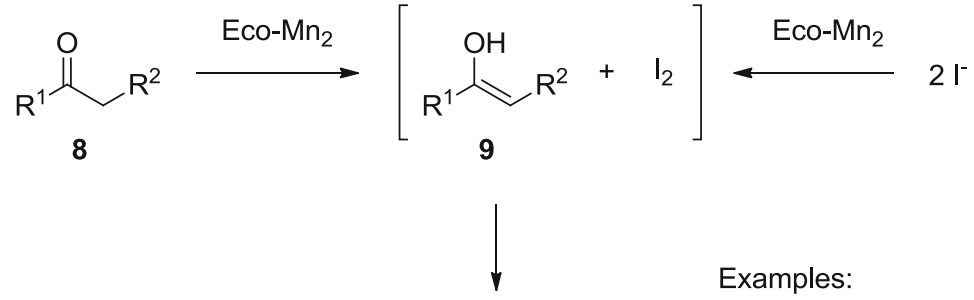<smiles>[R]C(=O)C([R])I</smiles>

10<smiles>CCOC(=O)C(I)C(C)=O</smiles>

$100 \%$<smiles>O=C1CCCCC1I</smiles>

$64 \%$ 
<smiles>CC(C)=CCC[C@H](C)CC=O</smiles>

$(R)-(+)$-citronellal

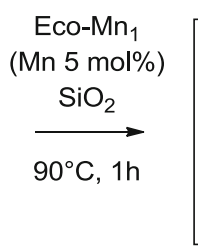

(R)-(-)-isopulegol

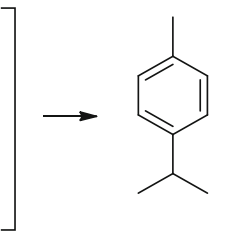

p-cymene

Scheme 6 Tandem ene reaction/dehydration/oxidation of (+)-citronellal into $p$-cymene

reduction of wastes and simplification of processes. During the course of these studies, we also discovered that Eco- $\mathrm{Mn}_{1}$, previously described only as a Lewis and Brønsted acid catalyst, could catalyze oxidation reactions, with dioxygen from air. The following examples illustrate thus the potential of the two Eco- $\mathrm{Mn}_{1}$ and Eco- $\mathrm{Mn}_{2}$ as Janus catalysts for sequential tandem oxidations (Fig. 8).

Oxidative iodination of ketones with Eco-Mn $\mathrm{Mn}_{2}$ Halogenated compounds are widely used as chemical precursors in a number of reactions (Meijere and Diederich 2004). In particular, $\alpha$-iodinated ketones exhibit great reactivity and give access to a large set of compounds, including heterocycles with pharmacological activity (Erian et al. 2003).

Among the classical methods of synthesis of $\alpha$ iodoketones (De Kimpe and Verhé 2010), some of the most frequently used imply the formation of electrophilic derivatives of iodine, by using $\mathrm{I}_{2}$ in combination with various oxidizing reagents, such as $\mathrm{SeO}_{2}$ (Bekaert et al. 2000), Ce(IV) ammonium nitrate (Horiuchi and Kiji 1988), or $m$ iodosylbenzoic acid (Yusubov et al. 2010). In spite of their efficiency, these methods make use of toxic or unstable oxidizing reagents, often inconsistent with the requirements of the Registration, Evaluation, Authorization and Restriction of Chemicals (REACH) regulation (European Commission

Table 6 Formation of $p$-cymene with Eco- $\mathrm{Mn}_{1}$

\begin{tabular}{|c|c|c|c|}
\hline Entry & Terpene & Catalyst $\mathrm{a}^{\mathrm{a}}$ & Yield $(\%)^{\mathrm{b}}$ \\
\hline 1 & & Eco-Mn $\mathrm{Mn}_{1} 0.05$ equiv. of $\mathrm{Mn}$ & 80 \\
\hline 2 & & Eco- $\mathrm{Mn}_{1} 0.15$ equiv. of $\mathrm{Mn}$ & 91 \\
\hline
\end{tabular}

${ }^{\mathrm{a}}$ Reaction conditions: terpene (1.0 mmol), silica gel $(100 \mathrm{mg})$, Eco-Mn1, $90{ }^{\circ} \mathrm{C}, 1 \mathrm{~h}$

${ }^{\mathrm{b}}$ Yield was determined by GC-MS with biphenyl as internal standard

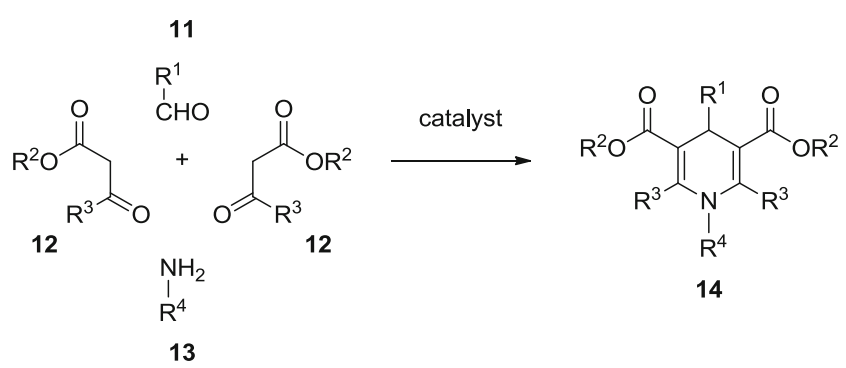

Scheme 7 The multicomponent Hantzsch reaction

2006). Moreover, as $I_{2}$ is a quite aggressive compound, its manipulation is problematic, especially on large scale. For example, the utilization of $I_{2}$ is strongly discouraged in industrial processes of iodination (Adams et al. 2013). For these reasons, various groups have proposed new methodologies implying the in situ formation of electrophilic species of iodine by oxidation of iodides, which are safe compounds (e.g., NaI, $\mathrm{KI}$ or $\mathrm{NH}_{4} \mathrm{I}$ ). Examples include the use of $\mathrm{NaI} /$ $\mathrm{H}_{2} \mathrm{O}_{2} / \mathrm{H}_{2} \mathrm{SO}_{4}$ (Barluenga et al. 2004), $\mathrm{KI} / \mathrm{air} / \mathrm{H}_{2} \mathrm{SO}_{4} / \mathrm{NaNO}_{2}$ (Stavber et al. 2008), or $\mathrm{NH}_{4} \mathrm{I} / \mathrm{Oxone}^{\circledR}$ (Reddy et al. 2011). Even if these methods represent significant improvements, they still make use of corrosive acids $\left(\mathrm{H}_{2} \mathrm{SO}_{4}\right)$ or very toxic compounds $\left(\mathrm{NaNO}_{2}\right)$. We thus decided to examine the potential of Eco- $\mathrm{Mn}_{2}$ in this reaction, as an alternative and safe oxidizing reagent, with $\mathrm{NaI}$ as iodine source.

Thanks to its Lewis and Brønsted acidity, Eco- $\mathrm{Mn}_{2}$ promoted the enolization of the ketone 8 . At the same time, the oxidizing properties of Eco- $\mathrm{Mn}_{2}$ allowed the in situ formation of $\mathrm{I}_{2}$, present in the reaction medium only as a temporary intermediate which was immediately consumed by reaction with the enolized ketone $\mathbf{9}$, forming the $\alpha$-iodoketone $\mathbf{1 0}$ (Scheme 5).

By using two equivalents of $\mathrm{Mn}$ from Eco- $\mathrm{Mn}_{2}$ under agitation at room temperature for $12 \mathrm{~h}$, the reaction was quantitative on $\beta$-dicarbonyl compounds. Under the same conditions, cyclohexanone was directly iodinated to give 2iodocyclohexanone 10b in $64 \%$ yield, confirming the activity of the system on less easily enolizable ketones. Eco- $\mathrm{Mn}_{2}$ is thus a valuable green alternative to more noxious or unstable oxidizing reagents, avoiding the use of strong acids and toxic species.

\section{Tandem carbonyl-ene cyclization and aromatization of citronellal to p-cymene}

The transformation of natural biomass materials (e.g., terpenes) into value-added chemical and fine chemical products, as recently described by Corma et al. (2007), is highly important, and such conversion via green catalytic processes remains a considerable challenge. Here, we describe the unexpected conversion of $(+)$-citronellal (biosourced starting material, cf. "Lewis/Brønsted acid catalysis with Eco-Mn1") into $p$-cymene under catalysis with silica-supported Eco- $\mathrm{Mn}_{1}$, in a solvent-free methodology. 
Scheme 8 Tandem DHP synthesis-oxidation into pyridine, catalyzed by $\mathrm{Eco}-\mathrm{Mn}_{1}$

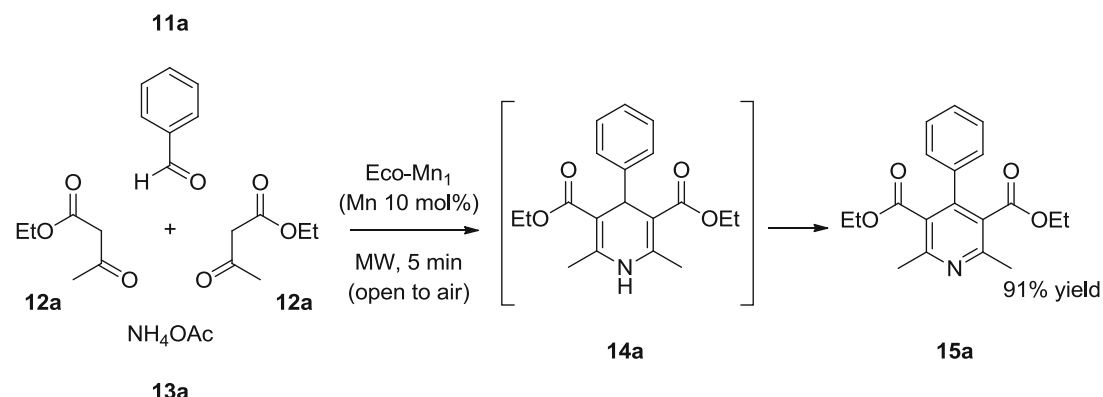

$13 a$
$p$-Cymene is used in a lot of industrial applications, as intermediate for the production of pesticides, fungicides, flavors, and pharmaceuticals (Fiege 2012; Roberge et al. $2001)$ or as a ligand in hydrogenation catalysts, such as $\left[\left(\eta_{6^{-}}\right.\right.$ cymene) $\left.\mathrm{RuCl}_{2}\right]_{2}$ (Tada et al. 2010). Currently, $p$-cymene is mainly produced by the Friedel-Crafts alkylation of toluene with 2-propanol and acid catalysts such as $\mathrm{AlCl}_{3}$ and $\mathrm{HCl}$ (Eggersdorfer 2012). This reaction is performed at high temperatures $\left(\geq 200{ }^{\circ} \mathrm{C}\right)$, produces unwanted isomers and multialkylation products, so that the yield of $p$-cymene usually does not exceed $50 \%$ (Barman et al. 2005). Moreover, the use of large amounts of hazardous acid catalysts and solvents gives rise to many problems, such as handling, safety, waste disposal, and corrosion, and are becoming more restricted by environmental legislation in industrialized countries. Thus, new pathways that avoid the continued use of these toxic reagents should be found.

Here, we propose an elegant one-pot and solvent-free process, starting from (+)-citronellal and leading to $p$-cymene. With a catalytic loading of only $5 \mathrm{~mol} \%$ of Mn from Eco-Mn ${ }_{1}$, dispersed on silica as solid medium, $p$-cymene was formed in $80 \%$ yield from (+)-citronellal, after heating to $90{ }^{\circ} \mathrm{C}$ for $1 \mathrm{~h}$ (Scheme 6 and Table 6, entry 1).

Eco-Mn $\mathrm{Mn}_{1}$ catalyst was used with the degree of oxidation of $\mathrm{Mn}$ present in the plant, i.e., $\mathrm{Mn}(\mathrm{II})$, but $\mathrm{Mn}(\mathrm{II})$ species are devoid of oxidizing properties and therefore cannot explain the observed aromatization. This result may be due to the presence of traces of oxidizing species such as $\mathrm{Mn}(\mathrm{III})$ or $\mathrm{Mn}(\mathrm{IV})$ in the G. exul rubiginosa-derived catalyst. Eco- $\mathrm{Mn}_{1}$ acted thus as a Janus catalyst, enabling to perform the

Table 7 The scope of the tandem DHP synthesis-oxidation into pyridine with Eco- $\mathrm{Mn}_{1}$

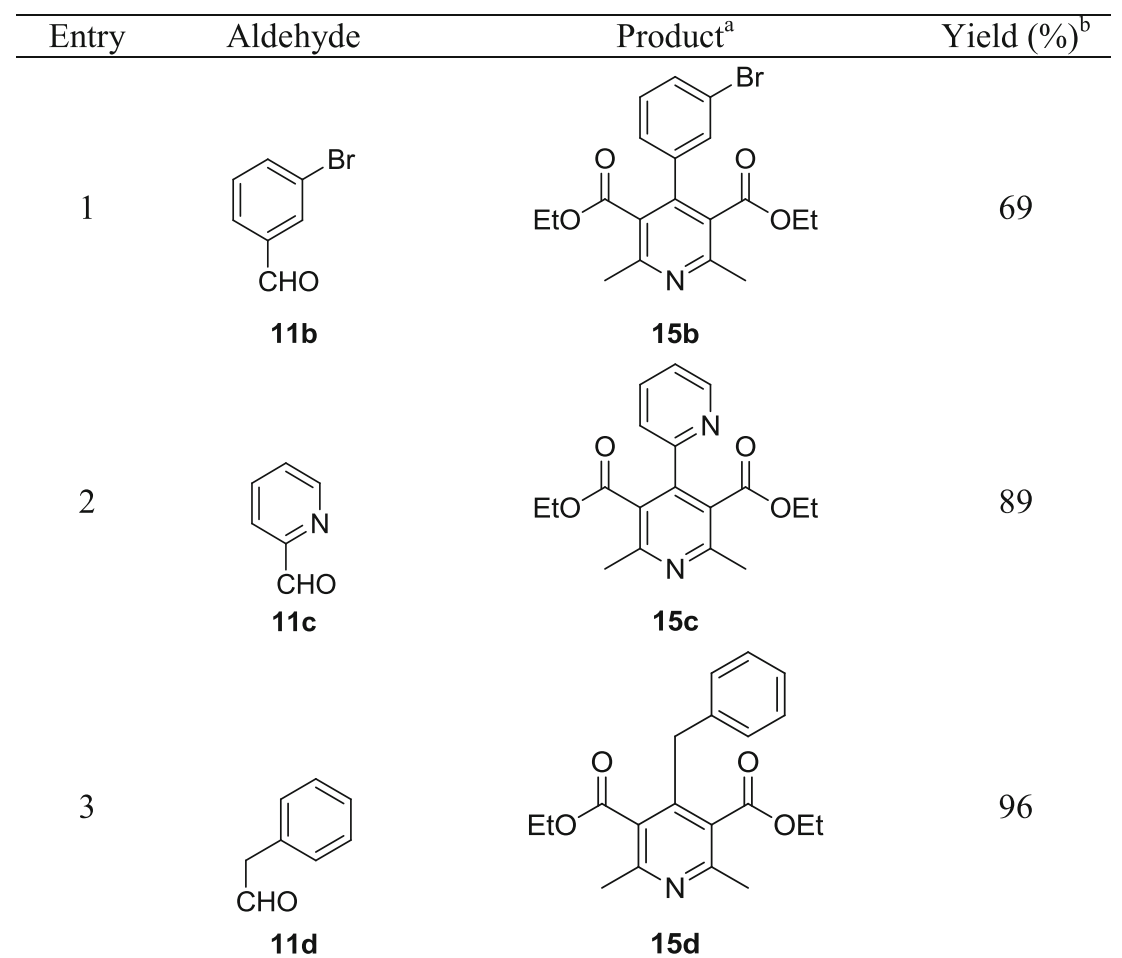

${ }^{\mathrm{a}}$ Reaction conditions: Eco-Mn $\mathrm{Mn}_{1}$ (amount corresponding to $0.05 \mathrm{mmol}$ of $\left.\mathrm{Mn}\right)$, silica gel ( $\left.1 \mathrm{~g}\right)$, aldehyde $(0.5 \mathrm{mmol})$, ethyl acetoacetate $(1.0 \mathrm{mmol})$, ammonium acetate $(0.75 \mathrm{mmol})$, MW irradiation $5 \times 1 \mathrm{~min}$ at $600 \mathrm{~W}$

${ }^{\mathrm{b}}$ Isolated yield 
carbonyl-ene reaction of (+)-citronellal into isopulegol (thanks to its Lewis acidity, as demonstrated by our previous infrared study), followed by dehydration of isopulegol into a cyclic alkene (catalyzed by the Brønsted acidity of Eco- $\mathrm{Mn}_{1}$, equally shown by the infrared study), then by aromatization into $p$ cymene, probably through a $\mathrm{Mn}(\mathrm{III})$ or $\mathrm{Mn}(\mathrm{IV})$-catalyzed oxidation $\left(\mathrm{O}_{2}\right.$ from air being the terminal electron acceptor). As Eco- $\mathrm{Mn}_{1}$ was initially conceived to contain Mn only under the form of $\mathrm{Mn}$ (II) species, we suppose that the traces of $\mathrm{Mn}$ (III) or $\mathrm{Mn}$ (IV) were formed by oxidation with $\mathrm{O}_{2}$ from air. Previous studies have indeed shown that whereas the oxidation of $\mathrm{Mn}(\mathrm{II})$ into $\mathrm{Mn}(\mathrm{III})$ or $\mathrm{Mn}(\mathrm{IV})$ by $\mathrm{O}_{2}$ from air is a very slow process, this transformation is highly accelerated in presence of traces of $\mathrm{Fe}$ (III) (Diem and Stumm 1984; Luther 2005). As Eco- $\mathrm{Mn}_{1}$ contains $0.90 \mathrm{wt} \%$ of $\mathrm{Fe}(\mathrm{III})$, the formation of such traces of $\mathrm{Mn}$ (III) or $\mathrm{Mn}(\mathrm{IV})$ in Eco- $\mathrm{Mn}_{1}$ by oxidation of $\mathrm{Mn}$ (II) with $\mathrm{O}_{2}$ from air is thus possible. Fe(III) being a oxidizing agent too, it is equally possible that this species participates with $\mathrm{Mn}(\mathrm{III})$ or $\mathrm{Mn}(\mathrm{IV})$ in the catalyzed oxidation.

Very few articles in the literature tell about the transformation of isopulegol into $p$-cymene, and these rare methods are not adapted to preparative synthesis (Bestmann et al. 1986). In order to validate the formation of $p$-cymene from isopulegol, we tested the action of Eco- $\mathrm{Mn}_{1} / \mathrm{SiO}_{2}$ catalysis on (-)isopulegol. $p$-Cymene was thus obtained with an excellent yield of $91 \%$ (Table 6 , entry 2 ).

This sequential tandem reaction is specific of Eco- $\mathrm{Mn}_{1}$ catalysis, where the evolution of isopulegol during its formation is unusual. None of the multitude of articles related to $p$ cymene synthesis refers to start from citronellal or isopulegol. This ecocatalyzed methodology is therefore the first to give access to $p$-cymene thanks to a sequential tandem oxidation combining three steps (carbonyl-ene reaction/dehydration/ aromatization) in one procedure. For these reasons, the method is in agreement with sustainable chemistry, especially with respect to the green chemistry principles that refer to the elimination of hazardous solvents and reagents, to energy efficiency and to the utilization of renewable raw materials (Anastas and Warner 1998). Work is under progress to further enlarge the scope and the mechanistic description of this methodology.

\section{Pyridine synthesis by Hantzsch reaction-aromatization with Eco-Mn}

Another example of sequential tandem oxidation is the direct synthesis of pyridines, obtained by oxidation of 1,4dihydropyridines resulting of the Hantzsch reaction.

1,4-Dihydropyridines (DHPs) have attracted the interest of the scientific community, because of their potential in various research fields. DHPs are indeed widely used as biomimetic reducing agents of a large set of chemical functions, thanks to their similarity with physiological hydrogen-transferring coenzymes (Liu et al. 2009; Nakamura et al. 1984; Rueping et al. 2005). Moreover, DHPs exhibit a number of pharmacological activities (Edraki et al. 2009). The rapid progress in synthesis and applications of DHP is regularly reported in review papers (Eisner and Kuthan 1972; Lavilla 2002; Saini et al. 2008; Stout and Meyers 1982; Wan and Liu 2012).

The multicomponent Hantzsch reaction (Scheme 7), described in 1882 (Hantzsch 1882), is one of the methods described for synthesizing DHP 14, under Brønsted or Lewis acid catalysis. Previously described catalysts include $\mathrm{Bi}\left(\mathrm{NO}_{3}\right)_{3} \cdot 5 \mathrm{H}_{2} \mathrm{O}$ (Bandyopadhyay et al. 2012), $\mathrm{I}_{2}$ (Ko et al. 2005), $p$-toluenesulfonic acid (Cherkupally and Mekala 2008), montmorillonite K10 (Zonouz and Hosseini 2008), $\mathrm{RuCl}_{3}$ (Suresh and Sandhu 2009), or $\mathrm{Yb}(\mathrm{OTf})_{3}$ (Wang et al. 2005).

As Eco- $\mathrm{Mn}_{1}$ was successfully used in acid-catalyzed reactions (see "Lewis/Brønsted acid catalysis with Eco-Mn1"), we decided to examine its efficiency in the Hantzsch synthesis of DHP. We chose to test Eco- $\mathrm{Mn}_{1}$ as catalyst of the reaction under microwave irradiation, after dispersion of the catalyst and reagents on silica gel. Surprisingly, we obtained only trace amounts of DHP 14a, but the corresponding pyridine 15a was formed in $91 \%$ yield (Scheme 8). As the reaction was performed in the presence of air, we assumed that the DHP 14a was synthesized thanks to the acid catalysis of Eco- $\mathrm{Mn}_{1}$ and then oxidized into pyridine $\mathbf{1 5 a}$ by $\mathrm{O}_{2}$ from air.

However, when using the same conditions, but starting from the corresponding DHP 14a, without addition of Eco$\mathrm{Mn}_{1}$, the DHP proved to be quite stable during heating, with formation of only $22 \%$ of the pyridine 15a. This result proves that the oxidation of DHP into pyridine results from the catalytic oxidizing activity of Eco- $\mathrm{Mn}_{1}$, which may be due to the presence of traces of the oxidizing species Fe(III) and/or of $\mathrm{Mn}(\mathrm{III})$ or $\mathrm{Mn}$ (IV) in Eco- $\mathrm{Mn}_{1}$, as described in the previous section (tandem carbonyl-ene cyclization and aromatization of citronellal). This is consistent with a previous report of oxidation of DHP into pyridines by Mn(IV), but in stoichiometric conditions (Vanden Eynde et al. 1995).

This reaction has been extended to some other structures, illustrating the scope of the methodology (Table 7).

Eco- $\mathrm{Mn}_{1}$ thus proved to be a very efficient catalyst for the tandem DHP synthesis-oxidation by $\mathrm{O}_{2}$ from air. This system could advantageously replace the classical oxidizing reagents used for the synthesis of pyridines from DHP, such as $\mathrm{SeO}_{2}$ (Cai et al. 2005), Ce(IV) ammonium nitrate (Pfister 1990), $\mathrm{HIO}_{3}$ or $\mathrm{I}_{2} \mathrm{O}_{5}$ (Chai et al. 2006), $\mathrm{HNO}_{3}$-bentonite (Garcia et al. 1993), or $\mathrm{KMnO}_{4}$ (Vanden Eynde et al. 1994), some of which may be inconsistent with the new environmental legislations because of their toxicity. Moreover, whereas these oxidizing reagents are used in stoichiometric proportions, Eco- $\mathrm{Mn}_{1}$ allows their substitution by a greener catalytic methodology involving $\mathrm{O}_{2}$ from air as green oxidizing reagent. 


\section{Conclusion}

G. exul rubiginosa grown on degraded mining sites proved to be a valuable source of Mn for chemical synthesis applications. By deliberately simple procedures, two plant-based extracts highly enriched in Mn were produced and characterized. ICP-MS and XRD analyses revealed that the Eco-Mn extracts contained original polymetallic complexes, which may account for the particular reactivity of these plant-based extracts in green synthesis. Eco- $\mathrm{Mn}_{1}$ displayed marked Lewis and Brønsted acidities which make it a very efficient catalyst in the preparation of ethyl enol ethers (82-96 \% yield) and in the carbonyl-ene cyclization of $(+)$-citronellal into isopulegol (95\% yield), with a higher selectivity toward (-)-isopulegol (90\%) than a number of commercial Lewis acid catalysts. Eco- $\mathrm{Mn}_{2}$ was produced by a simple procedure of oxidation of $\mathrm{Mn}(\mathrm{II})$ from Eco- $\mathrm{Mn}_{1}$ into $\mathrm{Mn}(\mathrm{IV})$, by using air as a green oxidizing reagent. The resulting Eco- $\mathrm{Mn}_{2}$ demonstrated the efficiency of an activated form of $\mathrm{MnO}_{2}$, strengthened by the presence of Lewis acids (Mn(II) and Fe(III) chlorides) formed during its preparation. As a result, Eco- $\mathrm{Mn}_{2}$ was used as a green and efficient oxidizing reagent for the controlled oxidation of allylic and benzylic alcohols into aldehydes and for the oxidative cleavage of a polyol in quantitative yield. Finally, the two Eco- $\mathrm{Mn}_{\mathrm{x}}$ acted as Janus catalysts by promoting sequential tandem oxidation reactions, thanks to their content in Lewis acids and oxidizing species. The new reactivity of EcoMn developed here was especially motivating since conventional and classic oxidative agents are strongly discouraged by $\mathrm{REACH}$ regulation. The resulting methodology combined these two activities in one unique material, offering great advantages in a sustainable perspective, with reduction of wastes and simplification of processes. Further experimentation would be required in order to fully determine the potential and the mechanistic action of the new plant-based catalysts, but there is no doubt that they will display very interesting properties for cutting-edge green chemistry, while contributing to the development of phytoremediation programs.

Acknowledgments The authors would like to thank the Agence Nationale de la Recherche (ANR, programme 11ECOT 011 01), the Agence de l'Environnement et de la Maîtrise de l'Energie (ADEME), the Centre National de la Recherche Scientifique (CNRS) and the Fond Européen de Développement Régional (FEDER) for financial support.

\section{References}

Adams JP, Alder CM, Andrews I, Bullion AM, Campbell-Crawford M, Darcy MG, Hayler JD, Henderson RK, Oare CA, Pendrak I, Redman AM, Shuster LE, Sneddon HF, Walker MD (2013) Development of GSK's reagent guides - embedding sustainability into reagent selection. Green Chem 15:1542-1549
Aizpurua JM, Juaristi M, Lecea B, Palomo C (1985) Reagents and synthetic methods - 40: halosilanes/chromium trioxide as efficient oxidizing reagents. Tetrahedron 41:2903-2911

Akiyama T, Morita H, Fuchibe K (2006) Chiral bronsted acid-catalyzed inverse electron-demand aza Diels-Alder reaction. J Am Chem Soc 128:13070-13071

Alaerts L, Seguin E, Poelman H, Thibault-Starzyk F, Jacobs PA, De Vos DE (2006) Probing the Lewis acidity and catalytic activity of the metal-organic framework [Cu-3(btc)(2)] $(\mathrm{BTC}=$ benzene-1,3,5tricarboxylate). Chem-A Eur J 12:7353-7363

Anastas P, Warner JC (1998) Green chemistry: theory and practice. Oxford University Press, Oxford

Andrade CKZ, Vercillo OE, Rodrigues JP, Silveira DP (2004) Intramolecular ene reactions catalyzed by $\mathrm{NbCl}_{5}, \mathrm{TaCl}_{5}$ and $\mathrm{InCl}_{3}$. J Braz Chem Soc 15:813-817

Artamonova IV, Gorichev IG, Godunov EB (2013) Kinetics of manganese oxides dissolution in sulphuric acid solutions containing oxalic acid. Engineering 5:714-719

Baker AJM, Brooks RR (1989) Terrestrial higher plants which hyperaccumulate metallic elements - a review of their distribution, ecology and phytochemistry. Biorecovery 1:81-126

Bandyopadhyay D, Maldonado S, Banik BK (2012) A microwaveassisted bismuth nitrate-catalyzed unique route toward 1,4dihydropyridines. Molecules 17:2643-2662

Barbot F, Miginiac P (1979) New way to vinylic ethers from acetals. Helv Chim Acta 62:1451-1457

Barluenga J, Marco-Arias M, Gonzalez-Bobes F, Ballesteros A, Gonzalez JM (2004): New reactions in water: metal-free conversion of alcohols and ketones into alpha-iodoketones. Chem Commun (Cambridge, U K), 2616-2617

Barman S, Maity SK, Pradhan NC (2005) Alkylation of toluene with isopropyl alcohol catalyzed by Ce-exchanged $\mathrm{NaX}$ zeolite. Chem Eng J 114:39-45

Bekaert A, Barberan O, Gervais M, Brion J-D (2000) Direct $\alpha$ iodination of ketones using iodine/ $\mathrm{SeO}_{2}$. Tetrahedron Lett 41: 2903-2905

Bestmann HJ, Kobold U, Vostrowsky O (1986) Gas-phase dehydration of para-menthenols by reaction gas-chromatography - correlation of the elimination products with heats of formation from force-field calculations. Liebigs Ann Chem 234-241

Brooks RR, Trow JM, Veillon J-M, Jaffré T (1981) Studies on manganese-accumulating Alyxia species from New Caledonia. Taxon 30:420-423

Buckingham J (1994) Dictionary of natural products. Chapman \& Hall, London

Cahiez G, Alami M, Taylor RJK, Reid M, Foot JS, Fader L (2001a): Manganese dioxide, encyclopedia of reagents for organic synthesis. Wiley

Cahiez G, Bélanger G, Boudreault J (2001b): Manganese(II) Chloride, Encyclopedia of Reagents for Organic Synthesis. John Wiley \& Sons, Ltd

Cai XH, Yang HJ, Zhang GL (2005) Aromatization of 1,4dihydropyridines with selenium dioxide. Can J Chem-Rev Can De Chim 83:273-275

Chai L, Zhao Y, Sheng Q, Liu Z-Q (2006) Aromatization of Hantzsch 1,4-dihydropyridines and 1,3,5-trisubstituted pyrazolines with $\mathrm{HIO}_{3}$ and $\mathrm{I}_{2} \mathrm{O}_{5}$ in water. Tetrahedron Lett 47:9283-9285

Chan T-H (1991) Formation and addition reactions of enol ethers. In: Trost BM, Fleming I (eds) Comprehensive organic synthesis: selectivity, strategy, and efficiency in modern organic chemistry. Pergamon, Oxford, pp 595-628

Chavez DE, Jacobsen EN (2003) Catalyst-controlled inverse-electrondemand hetero-diels-alder reactions in the enantio- and diastereoselective synthesis of iridoid natural products. Org Lett 5: 2563-2565 
Cherkupally SR, Mekala R (2008) $p$-TSA catalyzed facile and efficient synthesis of polyhydroquinoline derivatives through hantzsch multicomponent condensation. Chem Pharm Bull 56:1002-1004

Clark GS (2007) Aroma chemical profile: menthol. Perfumer Flavorist 38-47

Cobo S, Heidkamp J, Jacques PA, Fize J, Fourmond V, Guetaz L, Jousselme B, Ivanova V, Dau H, Palacin S, Fontecave M, Artero V (2012) A Janus cobalt-based catalytic material for electro-splitting of water. Nat Mater 11:802-807

Corma A, Iborra S, Velty A (2007) Chemical routes for the transformation of biomass into chemicals. Chem Rev 107:2411-2502

Da Silva KA, Robles-Dutenhefner PA, Sousa EMB, Kozhevnikova EF, Kozhevnikov IV, Gusevskaya EV (2004) Cyclization of (+)-citronellal to (-)-isopulegol catalyzed by $\mathrm{H}_{3} \mathrm{PW}_{12} \mathrm{O}_{40} / \mathrm{SiO}_{2}$. Catal Commun 5:425-429

Davi M, Lebel H (2009) Copper-catalyzed tandem oxidationolefination process. Org Lett 11:41-44

De Kimpe N, Verhé R (2010): Synthesis and reactivity of $\alpha$-halogenated ketones, $\alpha$-haloketones, $\alpha$-haloaldehydes and $\alpha$-haloimines (1988). Wiley, pp. 1-119

Dess DB, Martin JC (1983) Readily accessible 12-I-5 oxidant for the conversion of primary and secondary alcohols to aldehydes and ketones. J Org Chem 48:4155-4156

Diem D, Stumm W (1984) Is dissolved Mn-2+ being oxidized by O-2 in absence of Mn-bacteria or surface catalysts. Geochim Cosmochim Acta 48:1571-1573

Earnshaw C, Wallis CJ, Warren S (1979) Synthesis of E-vinyl and Z-vinyl ethers by the horner-wittig reaction. J Chem Socy-Perkin Trans 1: 3099-3106

Edraki N, Mehdipour AR, Khoshneviszadeh M, Miri R (2009) Dihydropyridines: evaluation of their current and future pharmacological applications. Drug Discov Today 14:1058-1066

Eggersdorfer M (2012) Terpenes. In: Gerhertz W (ed) Ullmann's encyclopedia of industrial chemistry. VCH, Weinheim

Eisner U, Kuthan J (1972) Chemistry of dihydropyridines. Chem Rev 72: $1-42$

Erian AW, Sherif SM, Gaber HM (2003) The chemistry of alphahaloketones and their utility in heterocyclic synthesis. Molecules 8:793-865

Escande V, Garoux L, Grison C, Thillier Y, Debart F, Vasseur JJ, Boulanger C, Grison C (2014a) Ecological catalysis and phytoextraction: symbiosis for future. Appl Catal B-Environ 146: 279-288

Escande V, Tomasz O, Eddy P, Grison C (2014b) Biosourced polymetallic catalysts: an efficient means to synthesize underexploited platform molecules from carbohydrates. ChemSusChem. doi: $10.1002 /$ cssc. 201400078

European Commission (2006) Registration, evaluation, authorization and restriction of chemicals (REACH). Regulation (EC) No. 1907/2006 of the European parliament and of the council. Off J Eur Commun L396(17):1-849

Fatiadi AJ (1976a) Active manganese dioxide oxidation in organic chemistry — part I. Synthesis 1976:65-104

Fatiadi AJ (1976b) Active manganese dioxide oxidation in organic chemistry - part II. Synthesis 1976:133-167

Fatiadi AJ (1986) The oxidation of organic compounds by active manganese dioxide. In: Mijs WJ, Jonge de CRHI (eds) Organic syntheses by oxidation with metal compounds. Plenum, New York, pp $119-260$

Feigl F, Anger V (1972) Spot tests in inorganic analysis. Elsevier, Amsterdam

Fernando DR, Woodrow IE, Jaffre T, Dumontet V, Marshall AT, Baker AJM (2008) Foliar manganese accumulation by Maytenus founieri (Celastraceae) in its native New Caledonian habitats: populational variation and localization by X-ray microanalysis. New Phytol 177:178-185
Fiege H (2012) Cresols and xylenols. In: Gerhertz W (ed) Ullmann's encyclopedia of industrial chemistry. $\mathrm{VCH}$, Weinheim

Fogg DE, Dos Santos EN (2004) Tandem catalysis: a taxonomy and illustrative review. Coord Chem Rev 248:2365-2379

Fränzle S (2010): Autocatalytic processes and the role of essential elements in plant growth, chemical elements in plant and soil: parameters controlling essentiality. Tasks for vegetation science. Springer, Netherlands, pp. 17-130

Gademann K, Chavez DE, Jacobsen EN (2002) Highly enantioselective inverse-electron-demand hetero-diels-alder reactions of $\alpha, \beta$ unsaturated aldehydes. Angew Chem 114:3185-3187

Garcia O, Delgado F, Cano AC, Alvarez C (1993) Oxidation of hantzsch esters using the new system $\mathrm{HNO}_{3}$ /bentonite and microwave irradiation. Tetrahedron Lett 34:623-625

Gassman PG, Burns SJ, Pfister KB (1993) Synthesis of cyclic and acyclic enol ethers (vinyl ethers). J Org Chem 58:1449-1457

Grison C, Escarré J (2011): Use of metal-accumulating plants for the preparation of catalysts that can be used in chemical reactions. patent references: WO2011/064487A1; PCT/FR2010/052451; CA2781832-A1; EP2504096-A1

Grison C, Escande V (2013a): Use of certain manganese-accumulating plants for carrying out organic chemistry reactions. WO 2014/016509 A1

Grison C, Escande V (2013b): Use of certain metal-accumulating plants for implementing organic chemistry reactions. WO $2013150197 \mathrm{~A} 1$

Grison C, Escande V, Petit E, Garoux L, Boulanger C, Grison C (2013) Psychotria douarrei and Geissois pruinosa, novel resources for the plant-based catalytic chemistry. RSC Adv 3:22340-22345

Guo X, Yu R, Li H, Li Z (2009) Iron-catalyzed tandem oxidative coupling and annulation: an efficient approach to construct polysubstituted benzofurans. J Am Chem Soc 131:17387-17393

Hantzsch A (1882) Ueber die Synthese pyridinartiger Verbindungen aus Acetessigäther und Aldehydammoniak. Justus Liebigs Ann Chem 215:1-82

Ho T-L (1975) Hard soft acids bases (HSAB) principle and organic chemistry. Chem Rev 75:1-20

Hoelderich WF, Kollmer F (2000) Oxidation reactions in the synthesis of fine and intermediate chemicals using environmentally benign oxidants and the right reactor system. Pure Appl Chem 72:1273-1287

Horike S, Dinca M, Tamaki K, Long JR (2008) Size-selective lewis acid catalysis in a microporous metal-organic framework with exposed $\mathrm{Mn}(2+)$ coordination sites. J Am Chem Soc 130:5854-5855

Horiuchi CA, Kiji S (1988) A new alpha-iodination of ketones using iodine-cerium (IV) ammonium-nitrate. Chem Lett 31-34

Huisgen R (1977) Tetracyanoethylene and enol ethers - model for 2+2 cycloadditions via zwitterionic intermediates. Acc Chem Res 10: $117-124$

Imachi S, Owada K, Onaka M (2007) Intramolecular carbonyl-ene reaction of citronellal to isopulegol over $\mathrm{ZnBr} 2$-loading mesoporous silica catalysts. J Mol Catal A Chem 272:174-181

Isler O, Lindlar H, Montavon M, Ruegg R, Zeller P (1956) Synthesen in Der Carotinoid-Reihe.1. Die Technische Synthese Von BetaCarotin. Helv Chim Acta 39:249-259

Iwahama T, Yoshino Y, Keitoku T, Sakaguchi S, Ishii Y (2000) Efficient oxidation of alcohols to carbonyl compounds with molecular oxygen catalyzed by n-hydroxyphthalimide combined with a Co species. J Org Chem 65:6502-6507

Jaffre T (1977): Manganese accumulation by plants on ultrabasic rocks in New-Caledonia. Comptes Rendus Hebdomadaires Des Seances De L Academie Des Sciences Serie D 284, 1573-1575

Jaffre T (1979): Manganese accumulation by New Caledonian proteaceae. Comptes Rendus Hebdomadaires Des Seances De L Academie Des Sciences Serie D 289, 425-428

Ko S, Sastry MNV, Lin C, Yao C-F (2005) Molecular iodine-catalyzed one-pot synthesis of 4-substituted-1,4-dihydropyridine derivatives via Hantzsch reaction. Tetrahedron Lett 46:5771-5774 
Kropp PJ, Breton GW, Craig SL, Crawford SD, Durland WF, Jones JE, Raleigh JS (1995) Surface-mediated reactions. 6. Effects of silicagel and alumina on acid-catalyzed reactions. J Org Chem 60:41464152

Kumar P, Kumar A (2010) An expeditious oxidative aromatization of hantzsch 1,4-dihydropyridines to pyridines using cetyltrimethylammonium peroxodisulfate: a phase transferring oxidant. Bull Korean Chem Soc 31:2299-2303

Lavilla R (2002) Recent developments in the chemistry of dihydropyridines. J Chem Soc-Perkin Trans 1:1141-1156

Lawrence BM, Hopp R (2006): Natural and synthetic menthol, mint. Medicinal and aromatic plants - industrial profiles. CRC

Lee DG, Ribagorda M, Adrio J (2001): Potassium permanganate, Encyclopedia of reagents for organic synthesis. Wiley

Lee TV (1991) Oxidation adjacent to oxygen of alcohols by activated DMSO methods. In: Trost BM, Fleming I (eds) Comprehensive organic synthesis: selectivity, strategy, and efficiency in modern organic chemistry vol. 7. Pergamon, Oxford, p 291

Ley SV, Madin A (1991) Oxidation adjacent to oxygen of alcohols by chromium reagents. In: Trost BM, Fleming I (eds) Comprehensive organic synthesis: selectivity, strategy, and efficiency in modern organic chemistry vol. 7. Pergamon, Oxford, p 251

Li ZL, Jung H, Park M, Lah MS, Koo S (2011) Manganese (III)-promoted tandem oxidation and cyclization of beta-keto ester derivatives of terpenoids. Adv Synth Catal 353:1913-1917

Liu Q, Li J, Shen XX, Xing RG, Yang J, Liu ZG, Zhou B (2009) Hydrogenation of olefins using Hantzsch ester catalyzed by palladium on carbon. Tetrahedron Lett 50:1026-1028

Losfeld G, Escande V, Jaffré T, L'Huillier L, Grison C (2012) The chemical exploitation of nickel phytoextraction: an environmental, ecologic and economic opportunity for New Caledonia. Chemosphere 89:907-910

Luther GW (2005) Manganese (II) oxidation and Mn(IV) reduction in the environment - two one-electron transfer steps versus a single twoelectron step. Geomicrobiol J 22:195-203

Lv WP, Lee KJ, Li JJ, Park TH, Hwang S, Hart AJ, Zhang FB, Lahann J (2012) Anisotropic Janus catalysts for spatially controlled chemical reactions. Small 8:3116-3122

Makin SM (1976) The enol ether synthesis of polyenes. Pure Appl Chem 47:173-181

McAllister GD, Oswald MF, Paxton RJ, Raw SA, Taylor RJK (2006) The direct preparation of functionalised cyclopropanes from allylic alcohols or $\alpha$-hydroxyketones using tandem oxidation processes. Tetrahedron 62:6681-6694

Meijere AD, Diederich FO (2004) Metal-catalyzed cross-coupling reactions. Wiley, Weinheim

Moreno-Vargas AJ, Fernandez-Bolanos JG, Fuentes J, Robina I (2001) Reactivity of polyhydroxyalkyl-heterocycles towards Lewis acids. Tetrahedron-Asymmetry 12:3257-3266

Nakamura K, Fujii M, Ohno A, Oka S (1984) Nad(P)+-Nad(P)H model. 52. Reduction of olefins by hantzsch ester on silica-gel. Tetrahedron Lett 25:3983-3986

Nakatani Y, Kawashima K (1978) Highly stereoselective preparation of 1isopulegol. Synthesis $147-148$

Ohloff G, Giersch W (1973) Conversion of vicinal diols into dicarbonylcompounds by manganese-dioxide. Angew Chem-Int Edit Eng 12: 401-402

Outram HS, Raw SA, Taylor RJK (2002) In situ oxidative diol cleavage-Wittig processes. Tetrahedron Lett 43:6185-6187

Parry EP (1963) An infrared study of pyridine adsorbed on acidic solids. Characterization of surface acidity. J Catal 2:371-379

Perlin AS (2006) Glycol-cleavage oxidation. Advances in carbohydrate. Chem Biochem 60:183-250

Pfister JR (1990) Rapid, high-yield oxidation of hantzsch-type 1,4dihydropyridines with ceric ammonium nitrate. Synthesis 1990:689690
Quesada E, Taylor RJK (2005) One-pot conversion of activated alcohols into terminal alkynes using manganese dioxide in combination with the Bestmann-Ohira reagent. Tetrahedron Lett 46:6473-6476

Quesada E, Raw SA, Reid M, Roman E, Taylor RJK (2006) One-pot conversion of activated alcohols into 1,1-dibromoalkenes and terminal alkynes using tandem oxidation processes with manganese dioxide. Tetrahedron 62:6673-6680

Reddy MM, Kumar MA, Swamy P, Narender N (2011) Oxidative iodination of carbonyl compounds using ammonium iodide and oxone (R). Tetrahedron Lett 52:6554-6559

Rhoads SJ, Chattopa J, Waali EE (1970) Double-bond isomerizations in unsaturated esters and enol ethers.1. Equilibrium studies in cyclic and acyclic systems. J Org Chem 35:3352-3358

Roberge DM, Buhl D, Niederer JPM, Holderich WF (2001) Catalytic aspects in the transformation of pinenes to $p$-cymene. Appl Catal AGen 215:111-124

Rosatella AA, Simeonov SP, Frade RFM, Afonso CAM (2011) 5Hydroxymethylfurfural (HMF) as a building block platform: biological properties, synthesis and synthetic applications. Green Chem 13:754-793

Roy A, Kundu D, Kumar Kundu S, Majee A, Hajra A (2010) Manganese (II) chloride-catalyzed conjugated addition of amines to electron deficient alkenes in methanol-water medium. Open Catal J 3:34-39

Rueping M, Sugiono E, Azap C, Theissmann T, Bolte M (2005) Enantioselective Bronsted acid catalyzed transfer hydrogenation: organocatalytic reduction of imines. Org Lett 7:3781-3783

Russell CE, Hegedus LS (1983) Palladium-catalyzed acylation of unsaturated halides by anions of enol ethers. J Am Chem Soc 105:943949

Saini A, Kumar S, Sandhu JS (2008) Hantzsch reaction: recent advances in Hantzsch 1,4-dihydropyridines. J Sci Ind Res 67:95-111

Serrano-Ruiz JC, Luque R, Sepulveda-Escribano A (2011) Transformations of biomass-derived platform molecules: from high added-value chemicals to fuels via aqueous-phase processing. Chem Soc Rev 40:5266-5281

Shing TKM (1991) Glycol cleavage reactions. In: Trost BM, Fleming I (eds) Comprehensive organic synthesis: selectivity, strategy, and efficiency in modern organic chemistry vol.8. Pergamon, Oxford, pp 703-716

Shono T, Matsumura Y, Tsubata K (1981) Electroorganic chemistry. 46. A new carbon-carbon bond forming reaction at the alpha-position of amines utilizing anodic-oxidation as a key step. J Am Chem Soc 103:1172-1176

Snider BB (1996) Manganese(III)-based oxidative free-radical cyclizations. Chem Rev 96:339-363

Snider BB, Meunier A, Legault CY (2001): Manganese(III) acetate, encyclopedia of reagents for organic synthesis. Wiley

Snider BB, O'Hare SM (2001) Tandem manganese(III)-based oxidative free-radical cyclizations terminated by addition to furans. Formal synthesis of 15-acetoxypallescensin-A. Synth Commun 31:37533758

Stanzione JF, Sadler JM, La Scala JJ, Reno KH, Wool RP (2012) Vanillinbased resin for use in composite applications. Green Chem 14: 2346-2352

Stavber G, Iskra J, Zupan M, Stavber S (2008) Aerobic oxidative iodination of organic compounds with iodide catalyzed by sodium nitrite. Adv Synth Catal 350:2921-2929

Stout DM, Meyers AI (1982) Recent advances in the chemistry of dihydropyridines. Chem Rev 82:223-243

Suresh KD, Sandhu JS (2009) New efficient protocol for the production of Hantzsch 1,4-dihydropyridines using $\mathrm{RuCl}_{3}$. Synth Commun 39: 1957-1965

Tada M, Muratsugu S, Kinoshita M, Sasaki T, Iwasawa Y (2010) Alternative selective oxidation pathways for aldehyde oxidation and alkene epoxidation on a $\mathrm{SiO} 2$-supported ru-monomer complex catalyst. J Am Chem Soc 132:713-724 
Takezawa E, Sakaguchi S, Ishii Y (1999) Oxidative cleavage of vic-diols to aldehydes with dioxygen catalyzed by $\mathrm{Ru}(\mathrm{PPh} 3) 3 \mathrm{Cl}_{2}$ on active carbon. Org Lett 1:713-715

Tanyeli C, Sezen B (2000) Manganese(III) acetate based tandem oxidation of various cyclic beta-alkoxy alpha, beta-unsaturated ketones. Tetrahedron Lett 41:7973-7976

Tanyeli C, Ozdemirhan D, Sezen B (2002) Manganese(III) acetate based tandem oxidation of various alpha and beta-alkoxy alpha, betaunsaturated ketones. Tetrahedron 58:9983-9988

Taylor RJK, Reid M, Foot J, Raw SA (2005) Tandem oxidation processes using manganese dioxide: discovery, applications, and current studies. Acc Chem Res 38:851-869

van der Ent A, Baker AJM, Reeves RD, Pollard AJ, Schat H (2013) Hyperaccumulators of metal and metalloid trace elements: facts and fiction. Plant Soil 362:319-334

Vanden Eynde JJ, Dorazio R, Vanhaverbeke Y (1994) Potassium-permanganate, a versatile reagent for the aromatization of hantzsch 1,4dihydropyridines. Tetrahedron 50:2479-2484

Vanden Eynde JJ, Delfosse F, Mayence A, Van Haverbeke Y (1995) Old reagents, new results: aromatization of Hantzsch 1,4dihydropyridines with manganese dioxide and 2,3-dichloro-5,6dicyano-1,4-benzoquinone. Tetrahedron 51:6511-6516

Wan J-P, Liu Y (2012) Recent advances in new multicomponent synthesis of structurally diversified 1,4-dihydropyridines. RSC Adv 2:9763-9777

Wang A, Jiang H (2010) Palladium-catalyzed direct oxidation of alkenes with molecular oxygen: general and practical methods for the preparation of 1,2-diols, aldehydes, and ketones. J Org Chem 75: $2321-2326$

Wang F, Song G, Li X (2010) Rh(III)-catalyzed tandem oxidative olefination-Michael reactions between aryl carboxamides and alkenes. Org Lett 12:5430-5433

Wang LM, Sheng J, Zhang L, Han JW, Fan ZY, Tian H, Qian CT (2005) Facile Yb(OTf)(3) promoted one-pot synthesis of polyhydroquinoline derivatives through Hantzsch reaction. Tetrahedron 61:1539-1543

Yip K-T, Yang M, Law K-L, Zhu N-Y, Yang D (2006) Pd(II)-catalyzed enantioselective oxidative tandem cyclization reactions. Synthesis of indolines through $\mathrm{C}-\mathrm{N}$ and $\mathrm{C}-\mathrm{C}$ bond formation. J Am Chem Soc 128:3130-3131

Yusubov MS, Yusubova RY, Funk TV, Chi K-W, Kirschning A, Zhdankin VV (2010) m-Iodosylbenzoic acid as a convenient recyclable hypervalent iodine oxidant for the synthesis of $\alpha$ iodo ketones by oxidative iodination of ketones. Synthesis 2010:3681-3685

Zaki MI, Hasan MA, Al-Sagheer FA, Pasupulety L (2001) In situ FTIR spectra of pyridine adsorbed on $\mathrm{SiO}_{2}-\mathrm{Al}_{2} \mathrm{O}_{3}, \mathrm{TiO}_{2}, \mathrm{ZrO}_{2}$ and $\mathrm{CeO}_{2}$ : general considerations for the identification of acid sites on surfaces of finely divided metal oxides. Colloids Surf A Physicochem Eng Asp 190:261-274

Zonouz AM, Hosseini SB (2008) Montmorillonite K10 clay: an efficient catalyst for Hantzsch synthesis of 1,4-dihydropyridine derivatives. Synth Commun 38:290-296 